Papers and Proceedings of the Royal Society of Tasmania, Vo1.109, 1975.

(ms. received 29.10 .1974 )

\title{
OBSERVATIONS ON SOME TASMANIAN FISHES: PART XXI
}

by E.0.G. Scott, Launceston

(with four tables and two text-figures)

\section{ABSTRACT}

Two new species are described and figured: Muraenichthys Zingowenah (Eche1idae), Arnoglossus armstrongi (Bothidae).

Four species are added to the Tasmanian 1ist: Kyphosus sydneyanus (Günther) (Kyphosidae), Kyphosus gibsoni Ogilby, Zebrias fasciata Macleay (first Tasmanian representative of Soleidae), Navodon degeni (Regan) (Aluteridae); accounts are given of material on which the records are based.

General observations are made on: Muraenichthys breviceps Günther (Echelidae: correlation of body ratios with total length), Muraenichthys tasmaniensis McCulloch (new material, comparison with $M$. t. smithi Whitley), Mitotichthys tuckeri (Scott) (Syngnathidae: new material), Zeus faber Linne (Zeidae: young example), Cytius ausiralis (Gunther) (Zeidae: specific determination in terms of some common1y employed criteria), Enoplosus armatus (White) (Enoplosidae: sample of 29 juveniles, table of dimensions, relative growth, coloration), Katswwonus pelamis Linné (Kafsuwonidae: specimen from Tamar river, disposition of finlets), Lophonectes galZus Gunther (Bothidae: comparison with published accounts), Brachionichthys hirsutus (Lacépède) (Brachionichthyidae: northern Tasmanian material).

\section{INTRODUCTION}

This paper follows the general plan of others in the series. Linear measurements, except where otherwise stated, are given in millimetres, the name of the unit commonly being omitted. The symbols $L s, L t, T L s$, TLt denote standard length, total length, millesimals of standard length, millesinals of total length, respectively. Standard deviation is calculated with $n$ degrees of freedom; derived statistics being computed from the value thus obtained. Registration numbers, unless otherwise roted, are those of the Queen Victoria Museum, Launceston. Certain other conventions are noted in earlier contributions.

Some routine measurements in several species of the lengths of spines and rays have revealed length-position patterns. These patterns and procedures in their investigation have been discussed in Part XIX (Scott 1974a, p. 248); where it is noted that the lengths (arithmetic or, usually, logarithmic) in a group of radial elements are frequently found to be a linear function of the serial numbers (arithmetic, or, usually, logarithmic) of the elements. Serial numbers counted from the most anterior element of the set or subset in the dorsal and anal, from the uppermost ray in the pectoral and caudal, from the ray farthest from the spine in the ventral are denoted by $N$, numbers counted in reverse by $N^{1}$.

\section{Fami1y ECHELIDAE}

References to Echelidae have been made in these observations in Parts II(1936), VI (1953), VIII(1957), X(1961), XI(1963), XIX(1974). To the two species accredited to the State in the Check-1ist (McCul1och 1929) - Muraenichthys breviceps Gunther, 1876, M. tasmaniensis McCulloch, 1911 (both with Tasmania as type locality), - M. australis Macleay, 1881 (type locality, New South Wales) was added in Part III (1936, p. 114) and M. ogilbyi Fowler, 1908 (type locality, Victoria) in Part XIX (1974). 


\section{Tasmanian Fishes}

A new species of Muraenichthys is here described. In the 1974 key to species recorded from Tasmania the new form would enter couplet 3; but is distinguishable immediately from the two species there entered by its low value for Schmidt's index (about 2; contrast about 18-22), and, more comprehensively, by certain other characters set out in table 1 below. Some observations are made on the correlation of certain body ratios with $L t$ in $M$. breviceps, and some dimensions of a specimen of $M$. tasmanien$s i s$ and of two specimens of $M$. australis are noted; some remarks are made regarding the status of the Western Australian $M$. tasmaniensis smithi (Whitley, 1944).

\section{Genus MURAENICHTHYS Bleeker, 1865}

Muraenichthys Bleeker, 1865, Nat. Tijdschr. Dierk., 2, p. 117. Orthotype, M. gymnopterus Bleeker.

Muraenichthys lingowenah sp. nov. (fig. 1)

Diagnosis. Attenuate; dorsal originating in advance of vent by about one-fourth head; head about five times in trunk; teeth (upper jaw) chief1y uniseria1, brief1y biserial anteriorly; heavily punctulated, darker above, no gross markings.

Principal dimensions. Length to base of caudal rays, $L s, 183.3 \mathrm{~mm}$, total length, Lt, $183.6 \mathrm{~mm}$. Dimensions that follow are given as Tlt (absolute measurement, $\mathrm{mm}$, in parentheses). Length to dorsa 1 origin $430(79.0)$, to vent (middle) $446(82.0)$, to anal origin $452(83.0)$. Head $70.3(12.9)$, snout $10.9(2.0)$, eye $5.4(1.0)$, interorbita1 6.0 (1.1), mouth cleft to end of rictal groove 25.1 (4.6), to angle of free gape 18.5 (3.4). Maximum depth of head 15.3 (2.8), of body 16.1 (2.95); depth at vent 13.6 (2.5). Maximum width of head 13.6 (2.5), of body 16.9 (3.1); width at vent $16.3(3.0)$.

Genera1 features. Body long, slender, depth 62.2 in Lt, subcylindrical anteriorly, becoming progressively compressed caudad, notably in the posterior one-third. Branchial sac extending somewhat beyond the general profile ventrally, scarcely so laterally, its depth about 1.1 its width, subequal to combined lengths of eye and snout. Gill opening sma11, subequal to pupil; infero-1ateral, its upper angle below lateral 1ine (here about equidistant from dorsal and ventral profiles) by its own oblique length, or a trifle more; its lower angle distant from that of its fellow by rather more than twice slit length. Head smal1, 5.4 in trunk, 14.2 in Lt; subcylindrical. Snout rounded dorsally, moderately acute, its length twice eye, 5.2 in head. Lower jaw imperfect anteriorly, but shorter than upper when perfect; with mouth closed, its tip evidently fitting up into palate just behind upper lip. Anterior nostril in upper 1ip, briefly tubular, overhanging front part of lower jaw. Posterior nostril a slit in upper 1 ip about at level of front of eye, overhung by a small downwardly directed flap. Eye moderate, a trifle longer horizontally than vertically, 2.5 in snout, 12.9 in head; closer to mouth cleft than to dorsal profile, its distance from the former about onefourth its own vertical dianeter; margin somewhat indeteminate, bounded below and behind by a low fleshy ridge. Interorbita 1 I.I eye, 11.7 in head, gent 1 y convex both antero-posteriorly and transversely. Normal free gape about to posterior border of eye, rictal groove to behind eye by about eye diameter. Teeth in upper jaw of moderate length, stout, conical, some a little recurved; uniserial, briefly and irregularly biserial anteriorly (probably similarly disposed in lower jaw; damaged); a.small irregular patch on vomer; on the palate in two well-developed 1 inear series, approximate anteriorly, diverging posteriorly. Head with a number of pores. Lateral Iine originating near front of branchial basket, above it slightly convex; inmediately behind basket about equidistant from dorsal and ventral profiles; on part of trunk rising to be decidedly nearer dorsal than ventral profile; in rest of its course caudad about equidistant from the profiles; represented by a conspicuous, narrow, grossly continuous ridge; a ridge similar in general appearance, joining anterior ends of the two lateral lines in a slightly forwardly convex are across occiput. 

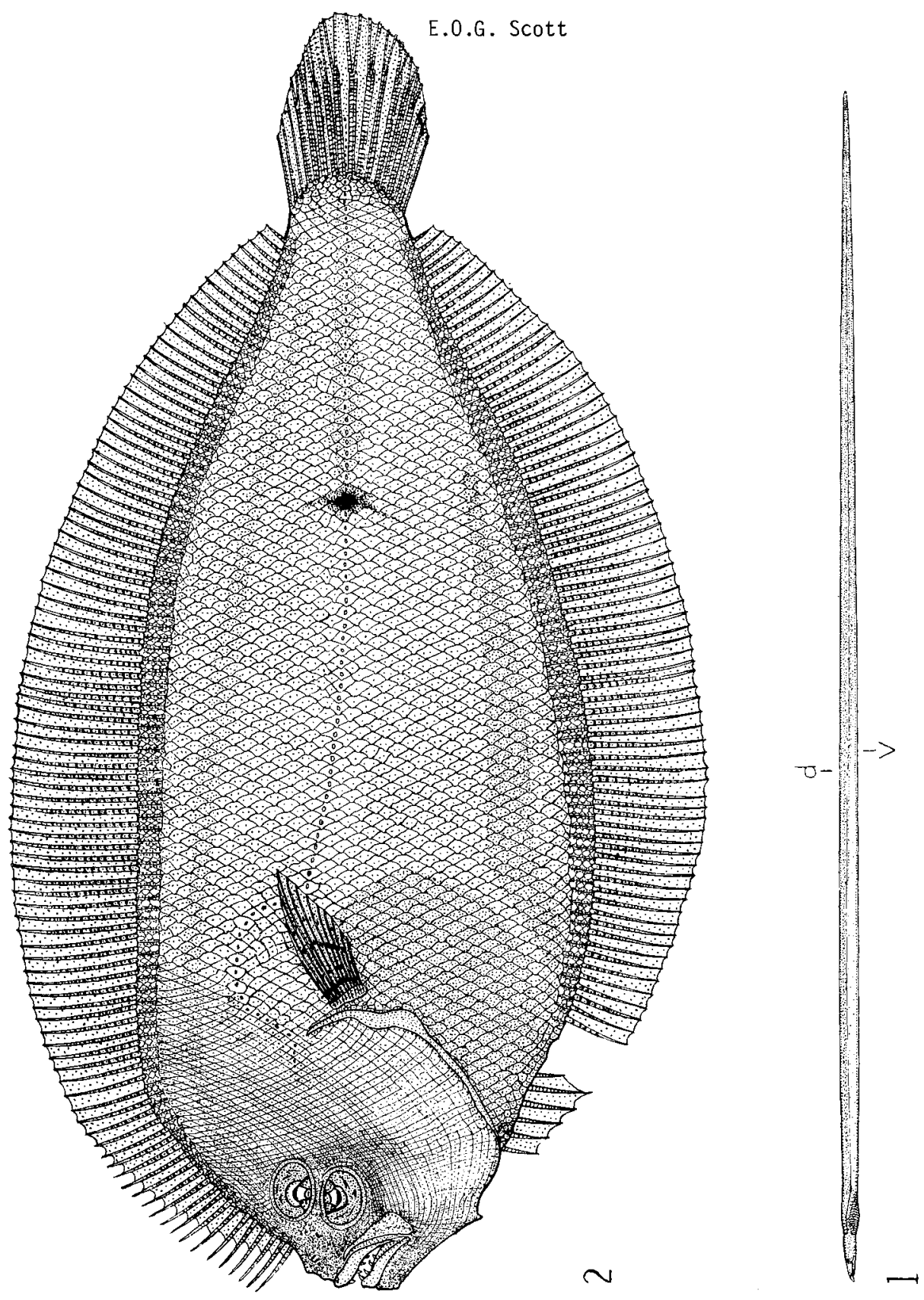

FIG. 1. - Muraenichthys Zingowenah sp. nov.; holotype; total 1ength $183.6 \mathrm{~mm}$; off Prime Seal Island, Furneaux Group, Bass Strait. Queen Victoria Museum Reg. No. 1974/5/58.

FIG. 2. - Arnoglossus armstrongi sp. nov.; holotype; standard length $168.5 \mathrm{~mm}$; Bridport, northern Tasmania. Queen Victoria Museum Reg. No. 1974/ $5 / 168$ 


\section{Tasmanian Fishes}

Fins inconspicuous, almost completely lapsed into grooves; evident1y 1ow. Dorsa1 originating in advance of vent by distance equal to combined snout and eye; at 0.96 of length of combined head and trunk, or 0.43 of total length. Schmidt's index, $S=$ $1.63\left(S=\frac{L v-L d}{I t}\right.$, where $L v=1$ ength to vent, $L d=1$ ength to dorsa1 origin, $L t=$ tota1 length). Dorsat and anal evenly confluent with a minute caudal fin with imperfectly developed rays and barely recognizable as a distinct entity.

Coloration. As preserved in formalin, dorsal and lateral surfaces of trunk and tail ranging from yellowish, with some tinge of greenish, anteriorly to pale orange or amber, still with some occasional hint of green, posteriorly; intense peppering with spots and splashes of reddish brown, confined in anterior portion of trunk to dorsal surface and lateral surface down to level of lateral line, extending progressively lower down caudad, reaching ventral profile at about middle of total length. Whole ventra 1 surface of trunk and tail amber or brownish orange.

Whole lateral and dorsal aspects of upper part of snout and intact (posterior) portion of lower jaw to level of posterior orbital border yellowish, with some tinge of greenish, punctulated abundantly, except for a small patch in front of eye and on much of lower jaw, with reddish brown; postorbital portion of head pale yellowish, punctulated and minutely flecked, somewhat less densely than anterior portion of head, with reddish brown; ventral surface mostly yellowish, immaculate, but with some dark punctulation on inferior surface of mandible.

Materia1. Described and figured (fig. 1) from the unique holotype, $183.6 \mathrm{~mm}$ in total length, $183.3 \mathrm{~mm}$ to base of degenerate cauda1, collected by Mr P. Armstrong off Prime Sea1 Island, Furneaux Group, Bass Strait, 24 August 1973; Q.V.M. Reg. No. 1974/ $5 / 58$.

The second binomen, Zingowenah, is one of two words for eel recorded in Milligan's vocabulary of the extinct Tasmanian aborigines (Ling Roth 1899), this being employed by tribes about Mount Royal, Bruny Island, Recherche Bay and the south of the island.

Affinities. Of the four muraenichthids hitherto recorded from Tasmania, only two, Muraenichthys breviceps Gunther, 1876, and $M$. ogilby $i$ Fowler, 1908, have the dorsa1 originating in advance of the anal. In both these forms the forward extension of the dorsal on to the trunk is considerable, being equal to, or greater than, length from tip of snout to fin origin, and being twice, or more, length of head: in the present species the corresponding values are less than one-twentieth and less than one-fourth. This approximation of dorsal origin to vent in $M$. Zingowenah is reflected in the low value for Schmidt's index, 1.63, values for the other species exceeding 15 . Two other noteworthy features exhibited by the new species are the extreme attenuation, greater than that hitherto precisely recorded for any Australian form (maximum depth upwards of 60 in Lt, ef. about 25-45) - Macleay noted of $M$. australis "Body very slender, its depth being about one-sixtieth of its length" (data given by McCulloch for the type specimen works out at depth about 45 in $L t$ )- and the small head (more than 5 times in trunk, of. about 3-4).

of the members of the genus recognized in the Handbook (Munro 1957a, p. 46) two other, non-Tasmanian species have dorsal origin on trunk, namely, $M$. devisi Fowler, 1908 (Victoria) and $M$. godeffroyi Regan, 1909 (Queensland). Difference between $M$. Zingowenah and the former include dorsal originating at 0.96 of distance between gill opening and vent (M. devisi 0.25), head $14.2(10)$ in $L t$, combined head and trunk 1.24 (1.5) in tail, eye $2.0(3.25)$ in snout; while Regan's species, for which few comparative data are available, clearly has a much more anteriorly inserted dorsal, and a decidedly larger head ( 3.2 in trunk, ef. 5.36 here).

Some comparative quantitative data on the three Tasmanian long-finned species are set out in table 1. Entries for $M$. ogizbyi are provided by the description of the type 
TABLE 1

Murdenichthys lingowenah sp. nov. Comparison of some proportions with those of $M$. breviceps Gunther, 1876 (8 Tasmanian examples) and $M$. ogilbyi Fowler, 1908 (holotype, 1 Tasmanian example). For details of Tasmanian material see text.

Feature

A

$\begin{array}{ccc}183.6 & 3.46 & 239 \\ 1.6 & 20.7 & 18.7 \\ 4.37 & 2.25 & 2.75 \\ 62.2 & 26.4 & 29.9 \\ 5.36 & 3.40 & 2.95 \\ 14.2 & 11.8 & 10.9 \\ 0.23 & 2.43 & 2.02 \\ 1.24 & 1.66 & 1.75 \\ 1.05 & 2.87 & 3.17 \\ 1.32 & 4.94 & 4.62\end{array}$

.62
Species

C

Total length, mm

Schmidt's index, $S$

Maximum depth in head

Maximum depth in tota 1 ength

Head in trunk

Head in total length

Head in dorsa1-bearing trunk

Precauda1 length in tail

Predorsal trunk in total trunk

Predorsal length in remainder of length

A. M. Zingowenah

B. M. ogizbyi: (i) holotype; (ii) Tasmanian example.

C. M. breviceps: (i) range; (ii) mean. 


\section{Tasmanian Fishes}

specimen from Victoria, Lt ca 346, and, more extensively, by a Tasmanian example (the first reported for the State), Lt 239, Green's Beach, January (R.H. Green), noted in Part XIX (1974, p. 161): those for $M$. breviceps by 8 individuals, as follows (a) Lt 583 lamar river at Blackwa11, 5 July 1935 (Lya11), (b) Lt 491, Stanley, received 28 February 1938 (B.C. Mol1ison), (c) - (f) Lt 393.3, 370.5, 313.5, 234.8, off Maat suyker Island, about November 1953 (J.R. Cowper), (g) Lt 439, Low Head, December 1960 (Miss A. Seager), (h) Lt 472.5, Derwent river at Long Point, Sandy Bay, 3 February 1961 (D.H. Hobbs). Individuals $(a)-(f)$ have been noted in Part VIII $(1957,150),(g)$, $(h)$ in Part XI $(1963,14)$, where accounts of them include some additional information on their sources of origin and the circumstances of their collection.

\section{Muraenichthys breviceps Gunther, 1876}

"1

Muraeniahthys breviceps Gunther, 1876, Ann. Mag. Nat. Hist., (ser. 4), 17, p. 401. Type locality: Tasmania (M. Allport).

Correlation of certain body ratios with $L t$. It is interesting to note that, even with the small sample of eight individuals, of the nine body ratios for this species entered in table 1 , no fewer than six exhibit systematic variation in magnitude with length of fish. As a measure of the correlation of each of these six ratios with Lt, there are given below, first, $r$ (with sign), secondly, $z$ (in parentheses), thirdly $t$, significance at levels of $P \leq 0.01, \leqslant 0.05, \leqslant 0.1$ being indicated by the addition to the $t$ of two asterisks, one asterisk, no asterisk, respective1y.

Schmidt's index $+0.918(1.578), 5.677 * *$; maximum depth in head $-0.704(0.876)$, 2.429; head in trunk $+0.899(1.469), 5.037 * *$; head in total length $+0.778(1.040)$, $3.103^{\star}$; head in dorsal-bearing trunk $+0.827(1.176), 3.604^{*}$; precaudal length in tail $-0.870(1.332), 4.316^{\star \star}$.

Symmetry of samples. As measured by the number of individuals occurring within the range $\overline{\bar{x}} \pm s$, all the samples of ratios in table 1 , together with Lt, are tolerably symmetrical. The number of entries within $\bar{x} \pm s$ for maximum depth in head and for head in trunk is 5; for all other ratios there listed, and for $L t, 6$ (cf., for infinite population, $\bar{x} \pm=5.5$ )

\section{Muraenichthys tasmoniensis McCulloch, 1911}

Muraenichthys tasmaniensis McCulloch, 1911, Zool. Res. Endecovour, 1, p. 19, fig. 5. Type locality, Oyster Bay, Tasmania.

Additiona1 material. Tasmanian material on which data are available are the holotype, Lt 170, and two examples, Lt 198, Lt 265, reported upon ear1ier in these Observations (1961, 1965). Some data are here presented on a larger individual, Lt 302, co11ected by $\mathrm{Mr}$ P. Armstrong off Prime Sea I Island, Furneaux Group, Bass Strait, 24 August 1973; Q.V.M. Reg. No. $1974 / 5 / 57$.

Dimensions. Values are given as Tlt, with absolute dimensions, mm, in parentheses. To provide some comparative data in connexion with remarks below on the status of the Western Australian $M$. tasmaniensis smithi (Whitley, 1944) Tit values for the type, Lt 275, and paratype, Lt ca 350, of that species are here given in square brackets. Length to vent 440 (133) [447, 440], to dorsal origin 488 (147.5) [491, 514], to anal origin 445 (134.5) [-, - ]. Head 73 (22) [84, 83]. Snout $11(3.3)[16,14]$. Eye 3.7 (1.1) $[7.3,6.4]$. Interorbital 6.3 (1.9) $[9.1,10]$. Mouth cleft to angle of free gape $17(5.0)$, to end of rictal groove $23(7.0)$ [as measured, 18, 17]. Depth at back of eye 8.3 (2.5), middle of branchial sac 21 (6.2), gill opening 18 (6.2), vent 15 (4.5); maximum depth $21[20,23]$ : widths at same points $13(3.9), 18(5.4), 16$ (4.8); maximum width $18(5.4)$. 


\section{E.O.G. Scott}

Comparative proportions. Some eight proportions of the holotype were given by McCulloch $(1911,19)$. His values are here followed by those for our three examples, all specimens in ascending order of magnitude of $L t$; followed in square brackets by those for the type and paratvoe of $M$. $t$. smithi. Depth in head 3.3. 3.5. 2.9. 3.7 $[4.2,3.6]$. Head in $L t 12.8,12.3,13.3,13.7[11.9,12.1]$, in trunk 4.3, 4.1, 4.7, $5.0[4.3,4.3]$. Eye in snout $3.2,3.8,3.4,3.0[2.3,2.4]$. Snout in head 4.8, 5.4, $5.8,6.7[5.1,5.8]$. Mouth $\mathrm{cleft}$ in head to end of rictal groove 2.7, 3.0, 3.0,3.1, to angle of free gape -, $-4.4[4.6,4.8]$. Length to vent in tail $1.4,1.42,1.28$, $1.27[1.23,1.27]$. Distance of dorsal origin from vent relative to head length 'equal to head', 0.8 head, $0.9,0.7[0.9,0.9]$.

Schmidt's index. No data for holotype, $6.60,2.64,4.80[4.36$, ca 7.43].

Status of $M$. t. smithi. Data set out above suggest some remarks on the status of $M$. t. smithi, which agrees with McCulloch's fish in having teeth in the jaws uniserial, but of which it is noted (Whitley 1944, p. 263) 'the snout is relatively shorter than in the Tasmanian type of Muraenzentnys tasmaniensis McCulloch ... and the gape of the mouth more extensive.' With regard to the first point, reference to the comparative proportions set out above shows that while the snout in Western Australian specimens is relatively shorter (compared with head length) than in the type (5.1, 5.8 in head; ef. 4.8) the same is true in all our three examples, one of which is as short as, one shorter than, the shorter of the two examples of $M$. $t$. smithi. McCulloch did not give any actual measurements (apart from $L t$ ): by double calculation, TZt value for snout of holotype comes out at 16 ( $c f$. Whitley's 16, 14). As regards mouth cleft, the above figures show that this is relatively less, not more, extensive in both whitley's specimens than in McCu1loch's type. The difference is not inconsiderable: however, it is to be noted that this dimension is subject to several possible interpretations, as the measurement can legitimately be taken, according to the convention adopted, either from tip of upper or of lower jaw to oral membrane connecting hinder parts of the jaws, or farther back to what may be regarded as normal angle of jaws, or farther back still to end of rictal groove. With cleft expressed in $T 2 t$ there is no great difference between the two Western Australian specimens $(18,17)$ and the present individual (23); however, values for the other Tasmanian examples, 27, 25, 29 (holotype computed), are noticeably larger. Comparison of the overall data of the four Tasmanian and the two Western Australian specimens (the latter themselves presenting some quantitative difference) thus suggests a distinct possibility that proportions recorded for $M$. tasmaniensis smithi may fall within the range of individual variation of $M$. tasmaniensis.

Muraenichthys australis Macleay, 1881

Muraenichthys australis Macleay, 1881, Proc. Linn. Soc. N.S.W., 6(2), p. 272. Type locality, New South Wales.

Additiona1 material. Quantitative data are available for only one Tasmanian example, Lt 272 , noted in Part III $(1936,114)$, constituting the first record for the State. Observations are here made on two other local examples, (a) Lt 318, Eaglehawk Neck, 1942 (Miss J.A. F1etcher), Q.V.M. Reg. No. 1942.13, (b) Lt 406, Binalong Bay, 18 June 1967 (Miss L. Webb), Q.V.M. Reg. No. 1967/5/12.

Dimensions. Values are given as Tlt, with absolute measurements, min, in parentheses. Length to vent $448,443(142.5,180)$, to dorsal origin $474,457(151,190)$, to anal origin $454,448(144.5,182)$. Head $73,83(23.1,33.6)$. Snout 13, $17(4.0,6.7)$. Eye $3.5,4.8(1.1,2.0)$. Interorbital $7.2,12(2.4,5.0)$. Mouth cleft to angle of free gape $18,23(5.1,9.5)$, to end of rictal groove $22,30(7.0,12.0)$. Depth at back of eye $9.1,15(2.9,6.10)$, middle of branchial sac $22,25(7.0,10.5)$, gil1 opening $27,27(8.5,11.3)$, vent $25,30(8.1,12.0)$; maximum depth, head 27, 28 (8.5, $11.3)$, body $25,30(8.1,12.0)$ : width at same points $9.4,14(3.0,5.7), 20,20(6.5$, $8.0), 22,25(7.0,10.0), 25,26(7.9,10.6)$; maximum width, head $22,25(7.0,10.0)$, body $26,30(8.2,12.0)$. 


\section{Tasmanian Fishes}

Comparative proportions. Beyond noting the depth was about one-sixtieth, the head one-fifteenth of the length, and the length to the vent one-fourth less than that to end of tail, Macleay (1881, p. 272) gave no dimensions. However, in a redescription of the type, Lt 248, McCulloch (1911, p. 20) recorded some proportions; four of which, two with some amplification, are adopted in the diagnosis in the Handbook (Munro 1957a, p. 46). Values for some important ratios are here set out for the three Tasmanian specimens, in ascending order of Lt, followed in square brackets by some data from McCulloch and Munro. Depth in head -, (behind head, probably not maximum, 3.9) 2.7, 2.8 $\lceil 3.3$ behind gi11 opening, 3.9 behind vent, McC.; 3.3, M.]. Head in Lt 12.1, 13.8, 12.1 [13, McC., M.; fifteen, Macleay]; in trunk 4.1, 5.2, 4.4 [4.5, McC., 4.5-5.3, M.]. Eye in snout 5.3, 5.8, 5.0 ['nearly 3', McC., 3-3.3, M.]. Snout in head 5.3, 5.8, 5.0 [5.3, McC.]. Mouth cleft in head to end of rictal groove 2.8, 3.3, 2.8 [2.7, McC.], to end of free gape $-, 4.3,3.5$. Length to vent in tail 1.39, 1.23, 1.26 [1.35, McC.; one and one-third, Macleay]. Distance of dorsal origin from vent, relative to head length, $0.13,0.37,0.30$ head.

Schmidt's index. $1.10,2.67,2.46$, al1 values negative.

\section{SYNGNATHIDAE}

MTTOTICHTHYS Whitiey, 1948

Mitotichthys Whitley, 1948, Rec. Aust. Mus., 22(1), p. 75. Orthotype, Syngnathus tuckeri scott.

Mitotichthys tuckeri (Scott, 1942)

Syngnathys tuckeri Scott, 1942, Rec. Queen Vict. Mus., I(1), p. 17, p1 5. Type locality: Bridport, northern Tasmania; netted in shallow water.

Mitotichthys tuckeri whitley, 1948, Rec. Aust. Mus. 22(1), p. 75. Id. Scott, 1960, Pap. Proc. R. Soc. Tasm., 94, p. 87 .

Syngnathus tuckeri Munro, 1958, Handok Aust. Fish., 20, p. 82, fig. 568 in Fisher. News2. (now Aust. Fisher.), 17, 2. Id. Scott, 1964, Pap. Proc. R. Soc. Tasm., 98, p. 93 .

Generic status. See Part IX $(1960,87)$, Part XII $(1964,93)$ : further consideration has led to the recognition here of the monotypic Mitotichthys Whitley, 1948. The chief points of distinction from Syngnathus Linné, 1758 are the location of the dorsal fin mainly on the trunk, and the much less extensive brood pouch (involving about 12, instead of 25 or more annuli). The relations of the present species with other Australian pipefishes should perhaps be the subject of further consideration.

New material. Data on five of the seven specimens that have previously come under the writer's notice, which are apparently the only examples in the literature, have been given in Parts IX, XII. Two additional examples, (a) ts 77.0, Lt 80.4, (b) Ls 100.0, Lt 104.5, were collected at Low Head, northern Tasmania on 16 Feb 1974 by Mr R.

Askeland; Q.V.M. Reg. No. 1974/5/100. This locality is in the same land division (formerly, county), Dorset, as the two localities (Bridport, Piper River Heads) from which four of the five earlier specimens came (rel.aining localities unknown); thus the species has yet to be reported from outside the eastern half of the island's northern coastline.

Meristic characters. Annuli 23+45, 23+43. Subdorsal annuli $10.0+2.0,8.9+2.4$. Brood annuli (b) caudal 0.1-12.5. D. 37, 36. F. 13, 13. A. ?, ?. C. $6,6$.

Dimensions and proportions. Measurements, $\mathrm{mm}$, (in parentheses, values as $T$ Zs). Head 


\section{E.0.G. Scott}

$10.5(136), 15.0$ (150); length to origin of dorsal 25.1 (326), 31.2 (312), to termination 35.6 (461), 46.1 (461); dorsal base 10.5 (136), 14.9 (149); 1ength to origin of brood pouch (b) 42.9 (429), to termination 57.5 (575); brood pouch base 14.6 (146); length to vent 32.1 (417), 42.0 (420); length of trunk 21.6 (281), 27.0 (270); length of tail $44.9(583), 58.0(580)$.

Measurements, mm (in parentheses, in head). Snout $5.0(2.1), 7.6(2.0)$; eye 1.3 (8.1), 1.9 (7.8); interorbita1 $1.0(10.5), 1.4(10.7)$; postorbital head 4.2 (2.5), $5.5(2.7)$; longest dorsal ray $3.1(3.4), 3.5(4.3)$; length of pectoral $2.0(5.3), 3.9$ (3.8); oblique length of pectoral base $1.7(6.2), 1.9(7.9)$; depth at opercular margin $2.9(3.6), 3.5(4.3)$, at middle of trunk $2.1(5.0), 3.0(5.0)$, at middle of tail 1.1 $(9.5), 1.8(8.3)$.

Eye in snout 3.9, 4.0. Snout in head 2.1, 2.0. Head in trunk 2.06, 1.80. Trunk in tail $2.08,2.15$.

Conspectus values. A conspectus of Tasmanian syngnathids (Scott 1961) provides, as the first eight entries for each species, the minimum and maximum values recorded in the literature for a count or proportion. Values there given, as emended by the 1964 data, are noted below, with further increases in range necessitated by the present material added in parentheses. Total annuli 22-23+40-43 (45). Subdorsal annuli 9-10+1.9-3. Brood annuli caudal 1 (0.1)-12.8. Dorsal 32-36 (37). Eye in snout 3.1-3.7 (4.0). Snout in head 1.9-2.1. Head in trunk $1.9(1.8)-2.2$ (Handbook (Munro 1958a, p. 82) gives 3 ; perhaps head in length to vent intended). Trunk in tail 2.1-2.5.

Estimates of dimensions from regression equations. Regression equations of region $(Y)$ on $L t(X)$ for eight regions, based on four individuals (together with correlation coefficient, measured and estimated values of regions; values of $t$ ) are set out in Part XII (table III, 94). Predicted values, mm, for the present two specimens are as follows: head $11.4,13.8$; snout $5.5,6.6$; eye $1.9,2.1$; postorbital head $4.1,5.2$; dorsal base $10.9,13.4$; length to vent $33.7,41.6$; trunk $22.2,27.8$; tail 46.7, 62.8 . Comparison with measured values recorded above shows these estimates are in general tolerably good.

In the equation for the regression of snout on $L t$ given in table III (1964) the independent term should be positive; in the equation for eye on $L t$ three, not two, zeros should follow the decimal point (fortunately, the fact that both estimated and observed values are systematically recorded renders these typographical errors evident.).

Coloration. The holotype, preserved in alcohol, had most probably undergone considerable change in color before description: the present specimens provide some interesting information on the point. Some notes on coloration in the holotype are here followed, in parentheses, first, by observations made on this material when in a tolerably fresh state, secondly by observations made after upward of six months' preservation in alcohol. Ground color 'pale horn' mostly yellowish olivaceous or light olivaceous; later, yellowish, or pale yellowish, green; 'a row of usually hemispherical whitish spots, one on each scute, along lower half of trunk' (spots lustrous silver; yellowish green: below midlateral ridge on anterior part of trunk an upper and a lower row of half-moons, their curved borders apposed); 'a whitish streak extending below eye along about one-third of infero-lateral angle of snout' (silver; light gold: this elongate pennon, starting from half an eye-diameter behind eye, covers whole of cheek below it, and runs forward, narrowing as it goes, for about two-thirds length of snout); 'dorsai and pectoral fins almost colorless' (dorsal faintly yellowish; yellowish in female, straw-colored with considerable streaky duskiness in male: pectoral almost colorless; golden or yellowish olivaceous).

In the present material the inferior border of the lateral surface of the tail 
and both borders of the ventral surface carried a silver strip that after a period of preservation became pale gold.

Brood pouch. This is fully developed but empty. It shows no indication of regression, suggesting the loss of ova was recent (possibly on capture). In one fold, almost black externally, very dark grey internally, there are 15 subcircular or polygonal cells with low whitish membranous walls, mostly uniserial, but with 3 in an inner row near middle.

Published data on the breeding season of nine Tasmanian syngnathids have been summarized in Part XVIII (1971, p. 123). The entry there for the present species is, ovigerous, 4 November 1959 (IX 1960, p. 88), ovigerous November 1965 (unpublished); to which may now be added, pouch empty, apparently recently ovigerous 16 February 1974.

\section{Family ZEIDAE}

The Checklist (McCulloch 1929, p. 135) and the Handbook (Munro 1957d, p. 76) each give four species to Tasmania - Zeus faber Linne, 1758, Zenopsis nebulosus (Temminck and Schlegel,1845), Cyttus australis (Richardson,1843), Cyttus novaeaealandiae (Arthur, 1885) [spelt novaezelandiae in Handbook], all of which have an extra-Australian range. Olsen (1958,p.157) has added a fifth species, Neocyttus rhomboidalis Gilchrist, 1906, as N. r. Gilchrist, var. gibbosus McCulloch, 1914, record based on an example with anal spines III (species is quite unusual in having a variable anal spine count, III or IV), caught in 1951 on long line in $100 \mathrm{fms}$ (ca $180 \mathrm{~m}$ ) off Maria Island.

\section{KEY TO ZEIDAE RECORDED FROM TASMANIA}

1. Bony spinigerous bucklers on dorsa 1 and anal profiles.

Dorsal originating in advance of opercular border $\ldots \ldots \ldots \ldots \ldots \ldots \ldots \ldots \ldots \ldots$

No such bucklers. Dorsal originating behind opercular

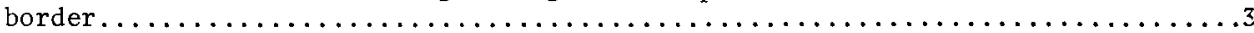

2. Scales. Anal spines IV, last free from, or barely

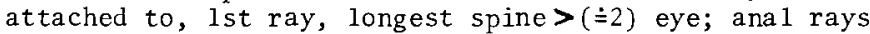
$24(21-23)$. Dorsal spines $x$; rays $<25(22-24) \ldots \ldots \ldots \ldots \ldots \ldots \ldots \ldots$. . . . faber Scaleless. Ana1 spines III, last attached to lst ray; longest spine<eye; anal rays $\gg 25(25-27)$. Dorsa 1 spines VIII-IX; rays $>25(27-28) \ldots \ldots \ldots \ldots \ldots \ldots \ldots \ldots \ldots$. $2 \ldots \ldots$. $2 \ldots$.

3. Ana1 spines III-IV, 1st spine $>\frac{1}{2}$ (subequal to) ventral spine. Dorsal originating behind ventral. Eye very large, reaching profile, $>\left(\doteq 1 \frac{1}{2}\right)$ first dorsal base......... Neocyttus rhomboidalis Anal spines II, lst spine $<\frac{1}{2}\left(\doteq 1 / 8-\frac{1}{4}\right)$ ventral spine. dorsa1 originating in advance of ventral. Eye large, but smaller, not reaching profile, $\leq$ first dorsal base................

4. Surface of scale with ridges and (in outer portion) spines, outer edge spinulate. Scales between lateral line and first dorsal $>12(\doteq 15) \ldots \ldots \ldots \ldots \ldots \ldots \ldots$
Surface of scale with ridges (may be denticulate) only, outer edge smooth. Scales between lateral line and first dorsal $<12(\doteq 9)$

Genus ZEUS Linné, 1758

Zeus Linné, 1758, Syst. Nat., ed. 10, p. 266. Ex Artedi, Ichthy., 1738. Logotype, Zeus faber Linné. 


\author{
E.O.G. Scott \\ Zeus faber Linné, 1758
}

Zeus faber Linné, 1758, Syst. Nat., ed. 10, p. 267. Ex Artedi. Type locality: 'Habitat in Pelago.'

Zeus australis Richardson, 1845, Zool. Voy. Erebus \& Terror, Fish, p. 36, pl. XXV, fig. 1. Type locality: Port Jackson, New South Wales.

Note on synonymy. The identity of the Australian and northern hemisphere fish, accepted in both the Checklist and the Handbook, whose example is here followed, is perhaps still open to some doubt. In his Name-list Whitley (1964, p. 41) recognises Richardson's species as the Australian form; he adopts the same name in his New Zealand Checklist (1968, p. 43).

Material. Whereas the silver dory, Cyttus australis (Richardson, 1843), is not infrequently submitted to the Museum for identification, examples of the John dory, like those of the New Zealand dory, Cyttus novaezelandiae (Arthur, 1885), are rarely seen. A sma11 specimen, Ls 97.0 , Lt 125.6 (species reaches a length of upwards of 600), taken off Ninth Island, northern Tasmania, on 8 September 1974 by Mr J. Shea (Q.V.M. Reg. No. 1974/5/166) exhibits some variation on the Handbook account (Munro 1957d, p. 76, fig. 527).

\title{
Fin counts. D. X,23. A. IV,23, P. 14/14, V. 1,7. C. $2+11+2$.
}

Principal dimensions. Values are given as Tis (absolute, mm, in parentheses). Length to origin, termination of first dorsal 424 (41.1), 732 (71.0) (spine); second dorsal 754 (73.1) (ray), 925 (89.7); anal, spinous segment 597 (57.9), 714 (69.3) (spine); anal, rayed portion $746(72.4)$ (ray), $899(87.2)$. Length to pectoral $355(34.4)$, length of $\mathrm{fin} 165$ (16.0). Length to ventral 253 (24.5), length of fin 478 (46.4). Length to vent (middle) 517 (50.2). Longest dorsal spine 311 (30.2), same with membranous filament 546 (53.0). Longest ray of dorsal 124 (12.0), of anal 123 (11.9), of pectoral (5th) 144 (14.0), of ventral (4th from spine) $412(40.0)$. Ventral spine 237 (23.0). Head 464 (45.0); snout, from tip of lower jaw (1ip) 201 (19.5), from tip of upper jaw (1ip) 186 (18.0), from most advanced point on preorbital 138 (13.4); eye 114 (11.1); interorbital 69 (6.7). Depth at front of eyes 402 (39.0), back of eyes 505 (49.0), operculum 588 (57.0), vent 603 (58.5); maximum depth 634 (61.5); depth of caudal peduncle $84(8.1)$.

Other features. Maxilla to below 0.1 eye; its greatest width 2.80 its 1 ength, 237 (23.0). Lower jaw projecting beyond upper; two stout spines, diverging from common base, close below symphysis. Ventral extending to 2 nd anal ray. Lateral line, particularly anteriorly, an almost continuous ridge, horizontal posterior segment, beginning about above 6 th anal ray, 2.85 in chord of anterior segment, 448 (43.5). Almost exactly hemispherical 'thumb-mark' behind operculum by about one-third postorbital head; diameter, without whitish annulus 114 (11.1), with annulus 137 (13.3); midpoint collinear with upper anterior edge of preorbital and middle of caudal peduncle; central portion evenly black, presenting no sign of 'containing an irregular lightcoloured figure' (Parrott 1959, p. 40). Marshall (1964, p. 133) observes, 'Smal1 specimens differ from larger ones in having much deeper bodies, marked with many wavy lines from snout to tail.' Our example, with length about one-fifth that of a large individual, is not deeper than a normal adult. However, it exhibits a juvenile color pattern in the form of from ten to a dozen rather wide, not noticeably wavy, longitudinal lines on the flank, not clearly apparent in the figure by Waite (1921, fig. 113) of an adult, reproduced in the Handbook (fig. 525), and of which there are no signs in the colored illustration by Roughley (1916, p1. 58): compared with those in the color photographs by Doak (1972, pl. 7) of the New Zealand fish noticed by him under the name Zeus japonicus, the stripes here are wider than in his upper illustration, but noticeably less definite and less clearly continuous than in his lower illustration. 


\section{Tasmanian Fishes}

Comparison with Handbook diagnosis. Fin counts fall within the Handbook ranges. Values for our specimen of the four proportions given by the Handbook (its values in parentheses) are depth in Ls 1.58 (1.6); head in Ls 2.15 (2.2); eye in snout, from tip of lower jaw 1.76, from tip of upper jaw 1.68, from front of preorbital 1.21 ('eye in snout 1.2'); eye in head 4.05 (3.5). The Handbook notes of anal, 'spinous part separate' and Scott (1962, p. 97) stated 'The four strong anal spines are separated from the soft portion of that fin.' In the present example a small but distinct membranous sheet connects the base of the last spine with that of first ray.

Fin patterns. With more rays than the usual 5, the ventral fin takes on a pattern often found in a pectoral with relatively few rays (and in a short or moderate spinous dorsal), presenting one ascending series (lengths increasing) with log lengths a linear function of $\log$ serial number $(N)$, and another series with 1 og lengths yielding a linear graph when plotted against logs of inverse serial numbers $\left(N^{\top}\right)$.

For subset rays $1-3 \log L=0.8880 \log N+1.1469$; measured (predicted) 1 engths, mm, $14.2(14.0), 25.1(26.0), 38.0(37.2) ; t=16.280$. For subset rays $4-7 \log L=0.131510 \mathrm{~g}$ $N^{1}+1.5207 ; 40.0(40.0), 38.2(38.5), 36.9(36.4), 33.0(33.2) ; t=11.389$.

In the John dory all the dorsal spines are rigid, though, as in the silver dory, these are surmounted by long very flexible filamentous extensions. While the lengths of these cutaneous appendages are probably indeterminate, the spines proper follow a familiar length-number pattern, with an ascending $N$ subset followed by a descending $N^{1}$ subset. For spines I-III $\log L=0.2724 \log N+1.3554$; spine lengths 22.5 (22.7), 27.9 $(27.4), 30.2(30.5) ; t=6.458$. For spines IV -X $\log L=0.5175 \log N^{1}+1.0546 ; 1$ engths 10.8 $(11.3), 17.0(16.2), 20.3(20.0), 24.5(23.3), 26.1(26.1), 28.0(28.7), 29.8(31.0)$; $t=18.968$.

Unfortunately three of the four anal spines are imperfect.

Genus CYTTUS Gunther, 1860

Cyttus Gunther, 1860, Cat. Fish. Brit. Mus., 2, p. 396. Logotype, Capros australis
Richardson.

Cyttus austrazis (Richardson, 1843)

Capros australis Richardson, 1843, Ann. Mag. Nat. Hist., 11, p. 170. Type 1ocality: Port Arthur, Tasmania.

Species differentiation. In the course of preparation of the key given above it was noted some characters commonly treated as diagnostic do not always hold good. An examination of a series of $13 \mathrm{fish}$ in the Queen Victoria Museum collection referred to Cyttus was accordingly undertaken, the following material being used (since the highly protractile mouth is more or less rigidly fixed in an extended condition in some individuals, rendering difficult an accurate determination of the whole length, two measurements of length of head, snouth, fish are here recorded, the first from anterior border of preorbital to hypural, the second, somewhat approximate, from tip of lower jaw; dimensions thus arrived at being designated short, ful1): (a) 106, 116, Tamar river, northern Tasmania, 24 June 1968, E.W. Gatenby, Q.V.M. Reg. No. 1968/5/28; (b) 119, 136, Tamar river, 24 June 1968, E.W. Gatenby, Q.V.M. Reg. No. 1968/5/29; (c) 146.5, 157, Beauty Point, Tamar river, 10 October 1965, E.W. Gatenby, Q.V.M. Reg. No. 1965/5/16; (d) 155, 166, northern Tasmania, 1930, T. Cannon, Q.V.M. Reg. No. 1937.87; (e) 172, 187, Anson's Bay, north-eastern Tasmania, 30 August 1969, G.A. Raynor, Q.V.M. Reg. No. 1969/5/27; (f) 183,198 , Bicheno, eastern Tasmania, 27 August 1972, Mrs D. Coles, Q.V.M. Reg. No. 1941.30; (h) 215, 226, off Cam river, north-western Tasmania, February 1973, H.J. Griffith, Q.V.M. Reg. No. 1973/5/30; (i) 223, 241, Tamar river, 23 October 1967, E.W. Gatenby, Q.V.M. Reg. No. 1967/5/28; (j) 256, 274, provenance not known; (k) 251, 269, Cape Lodi, eastern Tasmania, 13 May 1973, R.V. Bain, 


\section{E.0.G. Scott}

Q.V.M. Reg. No. 1973/5/100; (2) 345, 370, Beauty Point, Tamar river, 20 June 1972, A.E. Meek, Q.V.M. Reg. No. 1972/5/744; $(m) 440,490$, Burnie, north-western Tasmania, 6 February 1973, B. Thorp, Q.V.M. Reg. No. 1972/5/73.

Some basic dimensions and non-metrical characters are exhibited in table 2 .

The diagnostic features noted for C. australis in the Handbook are as follows, the corresponding entries for $C$. novaezealandiae, where these differ, here being shown in parentheses: (1) depth in length without caudal 5.1 .7 (1.6-1.7); (2) eye 2.75-3.2 (2.4) in head; (3) dorsal spines VII-X (VIII); (4) dorsal rays 28-33 (28); (5) spinous part of dorsal elevated (not much higher than soft part); (6) anal rays 31-37 (29); (7) fins pale carmine (spinous dorsal, ventral, caudal tip black) (8) ventral rays reaching 3 rd anal ray (not reaching anal origin). Additional Handbook features relevant here are: (9) head 3 in length without caudal [both species]; (10) from figures 527, 528, caudal convex (emarginate); (11) eye greater than snout [both species]; (12) front part of each scale striated [noted for C. novaezealandiae on 1y]. It may be observed that Stead (1906, 1908), Roughley (1916), Scott (1962) speak of the fins of $C$. australis as roseate, without direct mention of any black coloration.

Using the data of table 2, table 3 assesses the 13 specimens, assigning each of them to $C$. australis or $C$. novaezealandiae (or to both species, or neither), as determined on the basis of each of the 12 criteria listed in the preceding paragraph.

Proportions involving length of fish and length of head have been calculated twice, employing both the measurement from anterior border of preorbital and that from tip of lower jaw, and the two results are entered in the table (from an inspection of these it would seem evident the former mode of measurement is that adopted in arriving at the relevant Handbook proportions). For feature (9), relative length of head, the calculated value has been taken to be in agreement with the specified ' 3 in length without tail' when it is nearer to 3.0 than to 2.0 or 4.0 . In an attempt to obtain some quantitative assessment of (5), the spinous dorsal has been taken to be 'elevated' (as specified for $C$. australis) if its longest element is $(a)>2$ longest dorsal ray, or (b) 2 in base of soft dorsal, measured directly with callipers. With regard to (12), not entered in the tables,it is to be remarked the anterior part of the scale is striated in both species; but only in $C$. australis is the posterior part furnished (as in all present material) with spines (McCulloch 1911, p. 87). It has not been found feasible satisfactorily to tabulate entries for 'dorsal profile concave above eyes' (listed for $C$. novaezealandiae on $1 y$ ) in the absence of a more precise specification of the character. In general the section of the dorsal profile represented by the ends of the long backwardly-extending premaxillary processes is convex when these are retracted, but may appear concave when they are extruded; more ambiguously still, however, the degree of development (varying from very slight to considerable) of a short convex segment behind the eye results in the formation in advance of it of a local concavity, ranging from barely noticeable to quite pronounced, a feature that would or would not be regarded as significant according as the specification of a supraorbital concavity is interpreted.

Inspection of table 3 makes clear the inconstant, or otherwise unsatisfactory, nature of all or most of the characters there noted to which diagnostic significance has been attached in some published accounts - no specimen of the 13 examined being unequivocally identifiable, on the basis of these features, as $C$. australis, and all characters considered failing to prove critical in the case of one or more individuals. The low dorsal ray count, 26 , of specimen $(a)$ is quite exceptional. However, as noted above, all specimens are definitely determinable as $C$. australis by the nature of the scales, as reported by McCulloch; further, all are referable to this species by number of scales between lateral line and first dorsal base (15, McCulloch; our counts 14-17; cf. 9, McCu1loch, in C. novaezealandiae). 


\section{Tasmanian Fishes}

Two items in table 2, not redacted in table 3, namely, bulk and rigidity of second large free dorsal spine, call for comment. While the first large free dorsal spine (common1y 3rd spine, 1st being separate, very sma11, 2nd frequently being much longer, more or less completely fused with first conspicuous spine) is in some few instances tolerably stout, and often exhibits at least basally, some rigidity, the spine immediately following it is characteristically slender, flexible: specimens $(j)$ and $(2)$ are exceptional in having the latter spine short, massive rigid, stone-1ike, similar to the preceding, suggestive of early spines of $C$. novaezealandiae.

Fin patterns. These have been investigated for the ventral fin in specimens $(j),(k)$.

For $(j)$ rays $2-6$ on $\log s 1-5$ give the equation $\log L=0.4334 \log N^{1}+1.3015$; measured (calculated) lengths, mm, $19.6(20.0), 27.9(27.0), 32.4(33.2), 37.0$ (36.5), 39.1 (40.2); $t=19.129$ : for (k) $\log t=0.3582 \log N+1.4124$; 1engths $26.0(25.8), 32.9$ $(33.1), 38.2(38.3), 42.2(42.5), 46.5(46.0) ; t=27.050$.

In $(j)$ the spine, ray 6 , ray 5 yield a significant Iine ( $t=55.644$ ) on 1 ogs $1-3$,

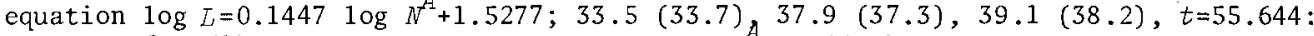
however, for $(k)$ the equation $\log L=0.2686 \log N^{A}+1.5448$ has a $t$ value of 8.420 on 1 y (i.e., probability of $0.1-0.5)$; lengths 34.8 (35.1), 43.1 (42.2), 46.5 (47.1).

\section{Family KYPHOSIDAE}

The Kyphosidae (not included in any published local 1ist) have hitherto been known to be represented in Tasmanian waters only by Kyphosus diemenensis Scott, 1971, the unique holotype of which was described and figured in Part XVIII of these Observations. Two additional species, $K$. sydneyanus (Gunther, 1866), K. gibsoni Ogilby, 1912 are here reported. The three species are satisfactorily separable by the key to the Australian members of the family given earlier (1971, p. 134).

\section{Genus KYPHOSIS Lacépède, 1802}

Kyphosus Lacépède, 1802, Hist. Nat. Poiss., 3, p. 114. Haplotype, K. bigibbus Lacépède.

$$
\text { Kyphosus sydneyanus (Günther, 1886) }
$$

Pimilepterus sydneyonus Günther, 1886, Ann. Mag. Nat. Hist (ser. 5), p. 18, p. 368. Type locality: Port Jackson.

Pimizepterus meridionalis Ogilby, 1887, Proc. Zool. Soc. Lond., p. 539. Type 1ocality: Port Jackson.

Tasmanian record. An example, Ls 215, taken at Croppies' Point, 28 December 1973, during the interstate spearfishing championships, provides the first record for this State; Q.V.M. Reg. No. 1974/5/163. The species has previously been known (Scott 1962, p. 193) from Western Australia, South Australia, New South Wales and Queensland.

Meristic characters. D. XI,12. A. III,11. P. 18/18. C. $18(2+14+2)$. V. I, 5 . Pierced scales of lateral 1ine 54, of which 2 are beyond hypural joint. About 63 rows of scales above lateral line between its origin and hypural joint, the anterior ones irregular; 51 rows between posterior margin of supraclavicle and hypural joint. Scales between origin of dorsal fin and lateral line 10; about 24 more to ventral surface. Predorsal scales about 55, small and confused on occiput and nape; eight behind level of upper end of operculum, here tolerably regular. Gill rakers on lower anterior arch 15, slender, closely set, longest a little less than half longest gill filaments, about one-third eye. 
TABLE 2

Cyttus australis (Richardson,1843). Some dimensions and other features of 13 Tasmanian specimens. 'Short; 'ful1' signify as measured from preorbital, from tip of lower jaw.

Key to symbols: E, emarginate; T, truncate or rounded; B, wholly or almost black; BW, approximately half black; b, touched with black; W, wi thout black; S, slender; M, massive; R, rigid; F, flexible.

Feature

Specimen

Short length

Full length (approx.)

Dorsal spines, number

Dorsal rays, number

Anal rays, number

Depth

Short head

Full head

Short snout

Fuli snout

Eye

First dorsal, base

First dorsal, color

Second large dorsal spine, bulk

Second large dorsal spine, rigidity

Longest dorsal spine

Longest dorsal ray

Ventral extending to (ana1)

Ventra1, color

Caudal, hind border, form

Caudal, hind border, color

\begin{tabular}{|c|c|c|c|c|c|c|c|c|c|c|c|c|c|}
\hline (a) & (b) & (c) & (d) & (e) & $(f)$ & $(g)$ & (h) & (i) & $(j)$ & $(k)$ & (l) & $(m)$ & \\
\hline 106 & 119 & 146.5 & 155 & 172 & 183 & 198 & 215 & 223 & 251 & 256 & 345 & 440 & \\
\hline 116 & 136 & 157 & 166 & 187 & 198 & 211 & 234.5 & 241 & 269 & 274 & 370 & 480 & \\
\hline VI I & IX & IX & V I I I & X & IX & IX & VI I I & IX & VI I I & VIII & VIII & VI I I & \\
\hline 26 & 29 & 29 & 29 & 30 & 29 & 29 & 31 & 29 & 31 & 31 & 30 & 31 & \\
\hline 29 & 29 & 30 & 29 & 31 & 30 & 31 & 31 & 28 & 30 & 31 & 30 & 31 & $\pi$ \\
\hline 69.5 & 75 & 87 & 94 & 104 & 110 & 122 & 126 & 115 & 140 & 127 & $18 \mathrm{I}$ & 197 & $\dot{0}$ \\
\hline 32.5 & 30 & 44 & 47 & 50 & 55 & 59 & 67 & 55 & 71 & 73 & $10 I$ & 144 & $\dot{\sigma}$ \\
\hline 42.5 & 47 & 54.5 & 58 & 65 & 70 & 72 & 78 & 73 & 89 & 92 & 126 & 184 & \\
\hline 10.2 & 10 & 14.5 & 14 & 17 & 19 & 19 & 18 & 20.5 & 25 & 23.5 & 33 & 41 & $\tilde{n}$ \\
\hline 20.2 & 27 & 25 & 25 & 32 & 34 & 32 & 37.5 & 38.5 & 43 & 42.5 & 58 & 81 & 움 \\
\hline 12.1 & 13.2 & 15.0 & 17.1 & 16.5 & 18.5 & 20.0 & 21.5 & 18.3 & 25.0 & 23.3 & 32.1 & 37.6 & \\
\hline 46 & 50 & 63 & 66 & 73.5 & 77.5 & 106.5 & 95.5 & 83 & 106 & 96.5 & 145.5 & 150 & \\
\hline $\mathrm{BW}$ & B & $B W$ & $W$ & BW & $\mathrm{BW}$ & $B W$ & W & W & BW & W & W & $W$ & \\
\hline$S$ & $S$ & $S$ & $\mathrm{~S}$ & $S$ & $\mathrm{~S}$ & $\mathrm{~S}$ & $S$ & $\mathrm{~S}$ & M & $S$ & $M$ & $S$ & \\
\hline $\mathrm{F}$ & $\mathrm{F}$ & $F$ & $\mathrm{~F}$ & $\mathrm{~F}$ & $\mathrm{~F}$ & $\mathrm{~F}$ & $\mathrm{~F}$ & $\mathrm{~F}$ & $R$ & $\mathrm{~F}$ & $R$ & F & \\
\hline 48.5 & 48.5 & $51+$ & 57.5 & $81+c a 10$ & $66.5+$ & $59+$ & 67 & $89+$ & 61 & 77.5 & 63 & 83 & \\
\hline 12.0 & 11.1 & 12.0 & 20.0 & 20.3 & 19.5 & 23.9 & 26.0 & 18.5 & 23.1 & 28.1 & 39.9 & 40.0 & \\
\hline spine/ & 2nd/ & lst & 2nd & 1st ray & 2nd & 2nd & - & lst & A-7nn & $1 \mathrm{st}$ & $\mathrm{A}-10.5 \mathrm{~mm}$ & $\mathrm{~A}-7.5 \mathrm{~mm}$ & \\
\hline ray & $3 x d$ ray & spine & spine & & ray & spine & & ray & & spine & & & \\
\hline B & B & B & BW & B & $\mathrm{BW}$ & $\mathrm{BW}$ & - & $\mathrm{BW}$ & B & $\mathrm{BW}$ & $\mathrm{BW}$ & $B W$ & \\
\hline E & - & $\mathrm{T}$ & - & E & E & - & - & $\mathrm{T}$ & E & $\mathrm{T}$ & E & - & \\
\hline$B$ & - & $\mathrm{b}$ & - & B & b & - & - & $W$ & B & B & W & - & \\
\hline
\end{tabular}




\section{TABLE 3}

Cyttus australis (Richardson,1843). Determination, on the basis of several common $1 y$ employed diagnostic characters - cf. Handbook (Munro 1957b, p. 76, figs 527, 528) - of 13 Tasmanian specimens of this species. 'Short', 'full' signify as measured from preorbital, from tip of lower jaw.

A, Cyttus australis; N, Cyttus novaezealandiae (Arthur, 1885); =, either species; $X$, neither species: blank cell, no datum available (specimen imperfect).

Specimen

\section{Feature}

No. Specification

(1a) Depth in short length

(1b) Depth in fu11 length

(2a) Eye in short snout

(2b) Eye in full snout

(3) Dorsal spines, number

(4) Dorsal rays, number

(5a) Spinous dorsal elevated, relative to dorsa 1 rays

(5b) Spinous dorsal elevated, relative to soft dorsal base

(6) Anal rays, number

(7a) Spinous dorsal, color

(7b) Ventral, color

(7c) Caudal, hind border, color

(8a) Ventral rays reaching to 3 rd anal ray (a) (b) (c) (d) (e) (f) (g) (h) (i) (j) (k) (z) (m)

$\mathrm{A}=\mathrm{A}=\mathrm{=}=\mathrm{X}=\mathrm{X} \mathrm{X}$ X X X

$\begin{array}{lllllllllllllllll} & X & X & X & X & X & X & X & X & X & X & X & X\end{array}$

$\begin{array}{lllllllllllll}X & X & A & X & A & A & A & A & A & A & A & X & X\end{array}$

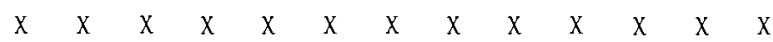

$\mathrm{A} A \mathrm{~A}=\mathrm{A} A \mathrm{~A} A \mathrm{~A}==$

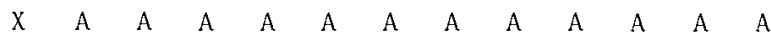

$\begin{array}{lllllllllllll}\text { A } & \text { A } & \text { A } & \text { A } & \text { A } & \text { A } & \text { A } & \text { A } & \text { A } & \text { A } & \text { A } & \text { N } & \text { A }\end{array}$

$\begin{array}{lllllllllllll}\text { A } & \text { A } & \text { A } & \text { A } & \text { A } & \text { A } & \text { A } & \text { A } & \text { A } & \text { A } & \text { A } & \text { N } & \text { A }\end{array}$

$\begin{array}{lllllllllllll}\mathrm{N} & \mathrm{N} & \mathrm{X} & \mathrm{N} & \mathrm{A} & \mathrm{X} & \mathrm{A} & \mathrm{A} & \mathrm{X} & \mathrm{X} & \mathrm{A} & \mathrm{X} & \mathrm{A}\end{array}$

$\begin{array}{lllllllllllll}\mathrm{N} & \mathrm{N} & \mathrm{N} & \mathrm{A} & \mathrm{N} & \mathrm{N} & \mathrm{N} & \mathrm{A} & \mathrm{A} & \mathrm{N} & \mathrm{A} & \mathrm{A} & \mathrm{A}\end{array}$

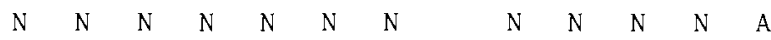

$\begin{array}{llllllll}\mathrm{N} & \mathrm{N} ? & \mathrm{~N} & \mathrm{~N} ? & \mathrm{~A} & \mathrm{~N} & \mathrm{~N} & \mathrm{~A}\end{array}$

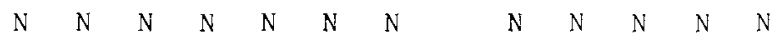

(8b) Ventral rays reaching to anal origin

(9a) Short head in length

$\begin{array}{llllllllllll}\text { A } & \text { A } & \text { A } & \text { A } & \text { A } & \text { A } & \text { A } & \text { A } & \text { N } & \text { A } & \text { N } & \text { N }\end{array}$

(9b) Fu11 head in length

(10) Caudal, form of hind border $N$

(11a) Eye, relative to short snout

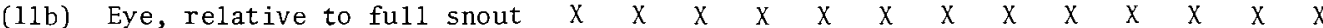


Principal dimensions as TZt. Total length 1233 , length to end of middle cauda 1 rays 1173. Length to origin, termination (base of spine) of first dorsal 330, 628; to origin, termination (bases of rays) of second dorsal 656, 828; to origin, temination of ana1 628,847 . Length to origin of pectoral 233 ; length of pectora1, direct from most advanced point on base to tip of 1 ongest ray 195, or from middle of base to tip of longest ray, 174. Length to origin of ventral 340; 1ength of ventral 205 . Length to vent (middle) 591. Head 256; snout 65; eye 65; interorbita1 116; internarial (anterior nostrils) 65. Depth (in parentheses width) at front of eyes 181 (112), back of eyes 279 (163), pectoral origin 391 (191), opercular margin 409 (205), ventra1 origin 437 (223), vent 451 (205); maximum depth (width) 465 (233); depth of caudal peduncle 142, width at anal termination 130 , at hypural joint 47 .

Length of ventral spine 111; of rays $1-5109,129,167,182,172$ [first ray here taken to be that furthest from spine $(1974,248)$ : in description of holotype of $K$. diemenensis (1971p.137) series is given in reversed sequence]. Lengths of dorsal spines. I-XI $33,60,89,115,-, 125,120,-, 100,74,52$; of rays $1-1272,78,91,95$, $101,84,91,93,102,102,107,123$. Lengths of ana 1 spines I-III 49, 61, 71; of rays $1-1182,98,106,107,98,85,84,80,84,80,92$. Lengths of pectora 1 rays $1-1780$, $145,167.173 .169,172,169,135,149,144,133,125,112,83,74,65,56$.

Comparative proportions. In the course of a detailed description, accompanied by an excellent figure, of an example $245 \mathrm{~mm}$ long from near Sydney McCulloch (1927, p. 56, p1. 11, fig. 2) noted a number of body ratios. Our values for these are subjoined (McCulloch's figures in parentheses). Depth before ventrals 2.29 (2.1) in Ls. Head 3.91 (3.6) in $L \varepsilon$. Breadth at pectoral bases 2.05 in depth there, or 2.44 in maximum depth (2.5 'in the depth'). Eye 1.00 in (shorter than) snout, 1.79 (1.7) in interorbital, 3.93 (3.9) in head. Interorbital 2.20 (2.1), snout 3.93 (3) in head. Depth of peduncle 1.09 (1.4) in its length, 1.80 (2.1) in head. Sixth dorsal spine 2.04 (2.9), second dorsal ray 3.27 (2.4), pectoral, from most advanced point on base direct to tip of longest ray 1.31, from middle of base to tip of longest ray 1.47 ('pectoral' 1.5 ) in head. McCulloch observed 'This young example differs considerably in its general form from larger examples $770 \mathrm{~mm}$ in length', noting in particular a decrease in relative depth with age.

General features. Head, trunk, tail in ratio 25.6:33.5:40.9. Diagnosis of body-form, in terms of the system of Gregory (1928), mesosomatic, gasterion preapical, apex median, gasterion median, hypsinotic, nomopygidial, opisthion preuranic.

Base of soft dorsal 0.58 base of spinous dorsal, measured between parallels. Pectoral reaching halfway along adpressed ventral, or to below dorsal spines V-VI. Ventral extending to below dorsal spines IX-X, failing to reach vent by an interval equal to that between vent and anal origin. Jaws equal anteriorly. Maxillary 1 argely scaly, extending to just level of anterior border of orbit, its distal width 2.8 in its length, 0.9 its direct distance from eye. Teeth in jaws 24 above, 28 below; compressed, mostly subconical in outline, but several at ends of both series subtriangular or subrectangular.

McCul'loch's observation (1927, p. 57), 'Anal a little farther back than the soft dorsa1,' apparently refers to the rayed portion of the fin, his figure showing first anal spine about below last dorsal spine, as obtains in our specimen.

Coloration. General color olivaceous above lateral line, gradually lightening below to near ventral profile, there greyish. Ventral surface whitish, immaculate between just behind branchiostegal membrane and anal origin; in advance of this greyish, with small markings of darker grey, in general one on each scale; along anal base, like side of tail here, behind fin narrow immaculate strip of dirty whitish. On flank below horizontal level of upper orbital rim about 13 longitudinal rows of interrupted white or silvery stripes, constituted by short vertical lines or proconcave arcs (less conspicuous than in $K$. diemenensis); above leve1 of orbit stripes inconspicuous, not 


\section{Tasmanian Fishes}

readily traceable. A prominent almost black spot, nearly one-third eye diameter, at lower border of pectoral base, constituting exposed extension of a dark bar, almost an eye diameter in vertical extent, about one-third this anteroposteriorly, mostly hidden beneath fin.

Head with lateral surface in general concolorous with flank; most scales on operculum, and, less conspicuously, those on preoperculum with lighter centre; opercular border blackish, width of band in upper segment about one-third, in lower segment about one-tenth, eye diameter; preoperculum with a somewhat dusky marginal strip virtually continuous with dusky upper lip; narrow dark arc behind, and reaching slightly above, eye, continued forward below rather more than posterior half of orbit.

First dorsal membrane largely greyish, with some blackish splashes; spines much like membrane, free tips usually blackish. Second dorsal mostly dark brownish; somewhat olivaceous, especially proximally. Anal rather like second dorsal, but lighter portion more extensive, up to two-thirds height of fin; tips of rays blackish. pectoral chiefly greyish; briefly somewhat lighter proximally, this region followed by an obscurely defined arc somewhat darker than rest of fin. Ventral rays white or mostly whitish in basal half (first ray) or less than half, remainder ranging from dark brown to blackish; the basal white continued, except in first ray, along preaxial border of ray for from three-quarters to four-fifths of its length. Caudal greyish, somewhat olivaceous, proximally; distal half or so with some duskiness, deepest on middle rays.

Fin patterns. (See Introduction). In the present specimen rays V and VIII are imperfect, and no formulation is here suggested to include VI. Among the rest there can be recognised an ascending subset, comprising I-IV, and a descending subset, comprising VII-XI. For the former the best straight line for the regression of the logarithm of the length of the spine, $L$, on the logarithm of its serial number counting caudad, $N$, is $\log I=$ $0.8777 \log N+0.8594$ : measured lengths, $\mathrm{mm}$, (in parentheses, values predicted by equation) are $7.0(7.2), 13.0(13.0), 19.1(19.0), 24.7(24.4) ; t=4.823$. For the descending subset $\log L=0.5165 \log N^{1}+1.0574$ [ $N=$ serial number counting cephalad]; $11.2(11.4), 16.0(16.4), 21.0(20.1), 25.2(26.2) ; t=14.010$.

Anal spines - For the 3 anal spines $\log L=0.3336 \log N+1.0191: 10.5(10.5), 13.0$ (13.2), $15.2(15.1) ; t=16.350$.

Pectoral rays - These increase in length to 4 th, but this ray, somewhat unexpectedly, appears not to be an element of the ascending first subset, 1-3, but to belong to the lengthy descending subset $4-18$. For rays $1-3, \log L=0.6656 \log N+12440: 17.5$ (17.5), $28.0(27.8), 36.3(36.4) ; t=69.227$. For rays $4-18 \log L=0.7427 \log N+0.7347: 5.0$ $(5.4), 10.0(9.1), 12.0(12.0), 15.0(15.2), 18.1(17.9), 21.0(20.5), 23.0(23.0)$, $27.0(25.4), 28.9(27.8), 30.1(30.0), 32.4(32.2), 34.5(34.5), 36.0(36.4), 37.0$ $(38.5), 38.1(40.6) ; t=45.831$. Though the overal1 fit for the descending subset of 15 rays is very good, yielding an extremely high $t$ value, there is some suggestion the plot may not be strictly linear, a general concentration near the middle of the series of predicted values somewhat lower than measured lengths perhaps being indicative of a non-random slight curvature here: however, much of the total variation is attributable to two rays $(8,9)$, and the divergence from linearity may be non-significant. No comparable situation occurs in the subset of rays 4-19 in $P$. gibsoni noted below.

Ventral rays - No simple formulation (other than the obvious trivial one) involving spine and adjoining ray (5) has been found. For rays $1-4 \log L=0.37471$ og $\mathrm{N}+$ $1.3694: 23.5(23.4), 30.0(30.3), 36.0(35.3), 39.1(39.4) ; t=37.468$.

Kyphosus gibsoni Ogilby, 1912

Kyphosus gibsoni Ogilby, 1912, Mem. Q2d Mus. 1(1), p. 50. Type locality: Moreton Bay. 


\section{E.0.G. Scott}

Tasmanian record. K. gibsoni is reported in the Check-1ist (McCulloch, 1929, p. 238) from Queensland only. A Tasmanian example, Ls 262, netted by Mr T. Jenkins at Norfolk Bay, 13 May 1974, Tas. Mus. Reg. No. D. 1209, has been made available for examination through the much-appreciated good offices of Mr A.P. Andrews, Curator of Vertebrates, Tasmanian Museum, Hobart, and by his courtesy for notice here. The original description of the holotype from Queensland by Ogilby (1912) was 1ater supplemented by an account and a figure of it by McCulloch (1929). Little or no additional original morphological data on the species appears to be available; accordingly, a tolerably full account of the Tasmanian example is here offered.

Meristic characters. Values for the holotype, as given by Ogilby and 1 ater by McCu11och, where different from present figures, are noted in square brackets. D. X1,14 [XI,13 Ogilby]. A. III,12. P. 19/19 [18, Ogilby]. V. I,5. C. 1+15+1 [not recorded; 15]. Pierced scales of lateral line 58, of which 6 are beyond hypural joint [59 (6); 54]; about 67 [78, 75] rows of scales above lateral line between its origin and hypural joint; about 57 [68,62] between posterior margin of supraclavicle and hypura1 joint (in both cases anterior scales somewhat irregular); 1 . tr. 11/23 [12/21; 12/21]. Predorsal scales about 60, small and confused on dorsum of head, 21 beyond 1 evel of upper angle of operculum [not recorded].

Principa 1 dimensions as T2s. Total length 1302 (tip of upper caudal lobe), 1252 (tip of lower caudal lobe); length to end of middle caudal rays 1145 . Length to origin, termination (bases of spines) of first dorsal 355, 582; to origin, termination (bases of rays) of second dorsal 594, 874; to origin termination of anal (spine, ray bases) 607,866 . Length to origin of pectoral 229 ; length of fin, direct from most advanced point on base to tip of longest ray 183, from middle of base to tip of 1ongest ray 164 . Length to origin of ventral 305; length of fin 179. Length to vent (middle) 561 . Head 244; snout 73; eye 62; interorbital 108; internaria1 (anterior nostrils) 71. Depth (in parentheses width) at front of eyes 160 (107), back of eyes 239 (130), pectoral origin 326 (153), opercular border 343 (156), ventral origin 382 (176), vent 405 (157); maximum depth (width) 447 (176); least depth of caudal peduncle 111, depth at end of dorsal 160, width at anal termination 94, at hypural joint 34 .

Length of ventral spine 76 ; of rays $1-586,100,148,168,172$. Lengths of dorsal spines I-XI $21,38,61,75,97,-,-, 111,101,93,74$; of rays $1-13103,100,97,89$, $88,80,80,76,76,73,67,65,69$ (anterior ramus) or 81 (posterior ramus). Lengths of anal spines I-III $30,45,54$; of rays $1-12123,129,107,103,95,94,88,76,72$, $69,66,69$ (anterior ramus) or 84 (posterior ramus). Lengths of pectoral rays $1-19$ $53,137,164,170,164,156,147,137,130,123,118,104,99,89,79,72,58,46,31$.

Comparative proportions. Ogilby (1912) noted 16 length ratios of the holotype and McCul1och (1929) 13 of the same specimen; some of those common to the two accounts exhibiting some difference. A comparative' summary of the two sets of data reported for the holotype and values for the present example follow, Ogilby's figures being cited first, those for the Tasmanian fish last. Ogilby's 'length of body' is here assumed to signify standard length.

Maximum depth in $L s 2.33,-, 2.24$. Depth before ventrals in Ls, -, 2.6, 2.62; 'breadth before pectorals in depth' -, 2.1, 2.13 (depth before pectorals) or 2.93 (maximum depth). Head in Ls 4.2, 4.08, 3.91. Eye in snout 1.3, 1.1, 1.7; in interorbital $1.85,1.8,1.74$; in head $3.9,4.3,4.13$; in depth of cheek below eye 1.1, - , 1.30. Interorbital in head $2.1,2.3,2.38$. Snout in head $3.05,3.7,3.53$. Depth of caudal peduncle in its length (measured in our example to hypural joint) $-, 1.7,1.14$; in head -, 2.4, 2.31; in depth of body 4.25,--, 4.03. Pectora1 in head -1.6 , from most advanced point on base direct to tip of longest ray 1.33 , or from middle of base to tip of longest ray 1.49 ; in Ls $6.25,-, 5.46$ or 6.04 . Ventral in Ls 6.5, -, 5.57. Caudal in Ls 3.65, -, 3.97. Dorsal spine in head 2.15 (1 ongest), 2.3 (6th), 2.20 (8th, longest intact; 6th and 7 th imperfect) or 2.53 (5th). First dorsal ray in head 


\section{Tasmanian Fishes}

$2.7,-, 2.67$. Longest anal in head $3.9,-, 4.54$. Posterior anal rays in anterior 1.55 , ,- 1.45 . Width of distal extremity of maxillary in its length $2.66,-, 2.96$, or,-- , 1.13 its direct distance from eye.

Genera1 Description. Fead, trunk, tai 1 in ratio 25.6:30.5:43.9.

Body broadly elliptical; dorsal profile a trifle more arched than ventral; compressed, greatest width 2.3 in greatest depth; head obtuse, its depth at front of eyes 1.6 , at back of eyes 1.1 , at opercular margin 0.74 , in its length. Dorsal profile, as constituted by upper $1 \mathrm{ip}$ and adjoining segment, extending about two-thirds width of lip, moderately convex, a minor dip at junction of the two regions; immediately following, about at level of two-thirds of length to anterior nostril, abruptly, but briefly, steeper; thereafter to highest point, at level of last one-third of first dorsal base, a tolerably even convex sweep, slightly depressed at occiput, its chord about $25^{\circ}$ to horizontal; thence descending, in a similar curve, to end of soft dorsal before gradually easing out on caudal peduncle. Ventral profile to end of anal base an essentially continuous curve; behind vent similar to dorsal profile there, in advance of vent a little less convex, especially in hinder half of trunk. Caudal peduncle short, fairly stout, its greatest depth 1.4 its least, latter 1.1 in peduncle length or 2.0 in head. Eye extending into hind half of head by about one-tenth of its own diameter, its highest point below dorsal profile by a little less than two-thirds its diameter, the diameter 1.3 in depth of cheek vertically below orbit. Preorbita1, dorsum of snout to 1 evel of anterior nostril, chin to same level, lips, naked; these areas covered with minute vermicular elevations, and, except for lips, sprinkled with small pores. Anterior half of preorbital border entire, posterior half with small rather obscure crenulations, about 8 on right side, half as many on left; integument obscurely ridged. Nostrils approximate, interval between them subequal to diameter of anterior, about half distance of posterior from orbit; the anterior a vertically elliptical opening with slightly elevated margin, its distance from its fellow subequal to its distance from middle of eye, or from middle of margin of upper lip; the posterior a backwardly and upwardly oblique elliptical aperture, with low skinny lips, its opening continued backwards for a distance about equal to its major axis by a naked groove, progressively shallower backward. Preopercular border fluted and obscurely crenulated, most markedly at and near angle. Posttemporal obscurely crenulated. Operculum with two weak spines, one slightly above level of orbit, one about level with lower border of pupil. Maxillary mostly squamous, marginally naked; extending beyond $1 \mathrm{evel}$ of anterior nostril, just failing to reach eye; its distal width one-third of its length, equal to its least distance from orbit. Upper jaw barely in advance of lower. Lips broad, with characteristic generic form, width of upper half its length: a line from upper border of upper lip to base of last dorsal ray passes across middle of eye. Teeth in jaws glassy, in single series, 22 in upper, 26 in lower; most contiguous basally, rest virtually so; compressed, general outline approximating three-fifths of an ellipse, the apex well rounded, but three or four lateral teeth in each side of lower jaw somewhat more squarish; whole series regularly decreasing in size outwards. Minute teeth on vomer in a transverse elliptical patch; on each pterygoid in a longitudinal elliptical patch; on anterior part of each palatine in a smal1 group; on tongue, somewhat in advance of middle of its length, in a very broad proconvex arc, extending virtually whole width of tongue here, these teeth, like those on palate, yellowish. Gill rakers on lower $1 \mathrm{imb}$ of anterior arch 22 , rodlike, slender, increasing in length forwards, longest less than half gill filaments, about one-third eye.

Body covered with ctenoid scales, which extend on to most of head (see above), and almost entirely sheath soft dorsal and anal, barely encroaching, however, on bases of dorsal or anal spines. Entire pectoral base, whole length of lower rays, proximal half, or so, of middle rays covered with small scales similar to those on vertical fins. Base and most of length of ventral rays scaly. Proximal one-fourth of caudal covered with integument, the hinder border proconcave, bearing scales continuous with, but backwardly progressively smaller than, those of caudal peduncle; still smaller scales extending up the rays, in some cases for virtually their whole length. Lateral 


\section{E.0.G. Scott}

line closely following curve of back to end of spinous dorsal, its direct distance (callipers) here from base equal to postorbital head; caudad of this progressively approaching dorsal profile, its direct distance from this at end of soft dorsal base two-thirds that at beginning of that base; on caudal peduncle a little nearer dorsal than ventral profile. Openings on pierced scales circular or subcircular anteriorly, slit-like posteriorly.

Dorsal commencing above middle of pectoral, behind insertion of ventral by twothirds snout length; margin of spinous portion fairly evenly arched, but last spine more than three and a half times first, longest intact spine (VIII) 1.1 longest (lst) dorsal ray; margin of soft dorsal very slightly convex, rays decreasing in length from 1 st to 5 th, latter 1.2 in former, showing little variation in length from 6 th to $8 \mathrm{th}$, measureably decreasing again to $12 \mathrm{th}, 1.6$ in $1 \mathrm{st}$, the $13 \mathrm{th}$ increasing to 1.5 (anterior ramus) or 1.3 (posterior ramus) in 1st; rayed base longer than spinous base, latter, measured between parallels 1.24 , directly with callipers 1.32 , times former. Anal much like soft dorsal, but a little higher anteriorly, 1st ray 1.2 lst dorsal ray; originating about below 2nd dorsal ray, terminating virtually evenly with dorsal; base 1.08 soft, 0.88 in spinous, dorsal base; 3rd spine 1.2, 2nd 1.81 st, the 1astmentioned 8.5 in head; 2nd ray longest, 2.0 in head, then decreasing to 11 th, 1.9 in 2nd, the last ray longer, its anterior ramus 1.87 , its posterior 1.53 in 2 nd. Pectora1 base well in advance of dorsal and ventral origins, set at about $45^{\circ}$, its oblique extension subequal to eye; fin short, broad, ovate; extending to below dorsal spines V/VI; length from most anterior point of base to tip of longest ray 1.6 , 1 ength from middle of base to tip of longest ray 1.8 , in head; longest (4th) ray 1.6 , a trifle shorter than longest ventral ray; first two rays unbranched. Ventrals originating behind pectoral base by an interval subequal to anteroposterior extension of that oblique base; failing to reach vent by an interval equal to that between vent and anal origin; longest ray ( $5 \mathrm{th}$, adjacent to spine) 1.5 in head, 2.3 spine. Caudal deeply emarginate, anteroposterior extension of tip of upper lobe beyond tips of middle rays equal to that of middle rays beyond hypural; length 3.32 in Ls; 1obes pointed, upper extending beyond lower by nearly an eye diameter; caudal ridges well developed, oblique length from origin of upper to tip of upper lobe 1.36 head.

Immediately internal to ventral base a smal1, wholly separate pennon-1ike axillary lobe, its outer border 1.6 in inner border plus base; this combined length 5.2 basa 1 width or about four-fifths eye.

Coloration, as preserved. Lateral and dorsal surfaces of body dark olivaceous brown above, at its deepest approaching black; below midlateral line lightening somewhat, most markedly in lowest one-fourth, with some silvery tinge here derived from the scale markings; ventral surface ranging from whitish or pearly to isabelline. In lowest six or seven rows each scale with a large elliptical or pyriform light, more or less pearly marking, its major axis sloping backwards and upwards; the light broken 1 ines thus formed not being recognizable above level of upper end of pectoral base, two just being traceable on caudal peduncle: above midlateral line uniformly dark.

Head with dorsal surface and lateral surface down to level of superior border of orbit very dark, concolorous with dorsum and upper part of trunk; below this gradating on cheek to dark brown; an arc of lighter brown behind eye, continuing forward on to hinder part of band of smooth integument joining eyes above upper lip, middle of this band darker; operculum narrowly bordered with dark fawn, membrane mostly blackish; preoperculum margined with dark fawn, narrowly posteriorly, more widely but more obscurely ventra11y; narrow exposed strip of interoperculum light and dark brown with some small pearly spots; upper lip about concolorous with scaleless strip above it; lower 1 ip more or less slaty, darkest along upper border; isthmus noticeably lighter than adjacent parts, approaching whitish, with faint silvery tinge. Preserved portions of membrane of spinous dorsal dull violescent; exposed parts of spines white. Rayed dorsal and rayed section of anal almost uniform dark brownish, a trifle 1ighter distally, last anal ray lighter with some yellowish; membrane investing most of spines II and III 


\section{Tasmanian Fishes}

about concolorous with that of rayed part of fin, membrane investing spine I light fawn; briefly exposed tips of spines vitreous. Pectoral with narrow basal arc of dusky chestnut; rays thereafter dark brown about up to a proconcave arc from near base of lowest ray to distal one-fifth of longest (4th) ray; distad of this dusky silvery. Proximal half or so of ventral plumbeous; rest dark brown, approaching black at tip. Caudal not greatly different from anal and soft dorsal, but upper and lower rays tending to be somewhat lighter, middle rays somewhat darker.

Fin patterns. Dorsal spines VI, VIII are imperfect: the rest constitute one ascending subset, I-V, and one descending subset, VIII-XI. For the former $\log L=0.96071 \log \mathrm{N+}$ 0.7273: measured lengths, mm, (in parentheses, values from equation) $5.4(5.3), 10.0$ $(10.4), 16.0(15.3), 19.7(20.2), 25.3$ (25.1); $t=17.310$. For the $\operatorname{latter} \log L=0.2837$ $\log N^{+}+1.2992: 19.5(19.9), 24.4(24.0), 26.5(26.7), 29.1$ (28.8); $t=5.199$.

Anal spines - $\log L=0.5315 \log N+0.9005: 7.9(8.0), 11.7(11.5), 14.1$ (14.3); $t=19.645$.

Pectoral rays - As in $K$. sydneyanus, these increase in length to 4 th, but again this ray is a member of the descending subset. For rays $1-310 \mathrm{~g} L=0.612710 \mathrm{~g} N+1.3247$ : $21.0(21.1), 32.8(32.3), 41.0(41.4) ; t=24.898$. For rays $4-1910 \mathrm{og} L=0.615510 \mathrm{~g} N+$ $0.8946: 8.0(7.8), 12.0(12.0), 15.1(15.4), 18.8(18.4), 20.8(21.1), 23.3(23.9)$, $26.0(26.9), 27.3(28.2), 30.9(30.3), 32.2(32.4), 34.1(34.3), 36.0(36.1), 38.6$ $(38.0), 40.8(39.8), 42.0(41.5), 43.0(43.2) ; t=61.532$.

Ventral rays - For rays $1-4 \log L=0.4862 \log N+1.5593: 22.5$ (22.9), 33.0 (32.0), $38.9(39.0), 44.1(44.8) ; t=18.805$.

Remarks. Kyphosus gibsoni is separable at sight from $K$. sydneyanus and $K$. diemenensis in having soft dorsal base exceeding spinous dorsal base, the former being about 0.58 of the latter in the first of these two species, about 0.74 in the second.

As the items of comparative quantitative data presented above make evident, the Tasmanian fish agrees in general quite well with the holotype as described by Ogilby, and redescribed and figured by McCulloch. While Ogilby observed 'sides with 8 bronzegold bands, about a third of a scale in width, and confined to the upper and lower edges of the mid-1ateral series of scales', and while McCulloch's plate appears to show upwards of a dozen bands on flank below lateral line, these light longitudinal bands are confined in the present specimen to side below level of upper end of pectoral base. The brief, but pronounced, elevation in dorsal profile before eye in our fish is scarcely indicated in McCulloch's figure of this species (1929, pI. XII, fig. 3), and is more conspicuous, and noticeably more abrupt anteriorly, than in the figure of $K$. sydneyanus on the same plate. Ogilby observes 'tongue smooth.' However - not unexpectedly, in view of the presence of lingual teeth in $K$. sydneycnus (holotype of $K$. diemenensis has tongue damaged) - the tongue, as noted above, here bears a wide cross-band of minute yellow teeth.

\section{Family ENOPLOSIDAE}

Genus ENORLOSUS Lacépède, 1802

Enoplosus Lacépède, 1802, Hist. Nat. Poiss., 4, p. 540. Haplotype, E. white Lacépède = Chaetodon armatus white.

\section{Enop Zosus armatus (White, 1790)}

Chaetodon cromatus White, 1790, Voy. N.S. Wales, p. 254, fig. 1. Ex Shaw MS. Type 1ocality: New South Wales [Checklist specifies 'Between Broken Bay and Botamy Bay']. 


\section{E. O.G. Scott}

Juvenile materia1. This species has been the subject of notice in Part XIX (1974a, p. 268), where some general observations are made on synonymy, venomous dorsal spines (cf. Scott 1970b, p. 239) and distribution; and a sample of six individuals, comprising one young, Ls 52.1, and five adult, Ls 161.7-221.0, is examined, a table of dimensions being provided, and some discussion of differnetial growth undertaken. The collection by Mr R. Askeland at Low Head, northern Tasmania, on 16 February 1974 of a sample of 29 very small individuals, all with $L s$ under 30 , affords a fortunate opportunity to record the (highly characteristic) juvenile coloration, and to confirm and extend earlier conclusions on relative growth at various morphological landmarks along the general anteroposterior axis.

Specification of Ls. For the whole sample (29) the range of Ls is 13.4-29.1, with mean $24.27+0.79(s 4.27+0.56, V 17.6+2.4)$. The large coefficient of variation points to probable heterogēneity, and insp̄ection of the frequency distribution - in $1 \mathrm{~mm}$ classes, $1,1,0,1,1,0,1,0,1,0,0,5,2,6,4,4,2$ - suggests the possible existence of two populations, one of 23 individuals of $L s 23.6-29.1, \bar{x} 26.23+0.34$ $(s 1.63+0.23, V 6.2 \pm 1.0)$ the other of 6 individuals of Ls $13.4-19.3, \bar{x} 16.79+1.07$ (s $\left.2.61 \mp 0.75, V 15.6^{-}+4.6\right)$. A formal test of the significance of the difference of the means yields $t 10.6002 \star \star$.

Specification of $L t$. For the whole sample $L t$ is $17.0-36.2, \bar{x} 30.85+1.01$ (s $5.43+$ $0.71, V 17.7+2.4)$, for 23 larger specimens $31.8-36.2, \bar{x} 33.40+0 . \overline{3} 4$ (s $1.63+0 . \overline{2} 4$, $V 4.9 \pm 0.7)$, for 6 smaller specimens $17.0-24.4, \bar{x} 21.08 \pm 1.43(s 3.5 \pm 1.01, \bar{V} 16.6$ $\pm 5.1)$.

Dimensions as T2s. About a score of measurements was made of each of 10 individuals: these dimensions, expressed as millesimals of standard length, are set out in table 4, together with $L s, \mathrm{~mm}$, (first line of table). Entries in the righthand column of the table showing the number of measurements falling within $\bar{X} \pm s$ make it evident the distribution of the varieties is tolerably symetrical.

Also, measurements of Ls, Lt, head, eye, maximum depth (on1y) were made of the remaining 19 specimens. Values of $L s$ and $L t$ for the full series of 29 have been given above. For 29 examples Tls specifications are: head $388-504, \bar{x} 435.1+5.39$ (s 29.00 $+3.81, V 6.7+0.9)$; eye $103-149, \bar{x} 121.6 \pm 1.92(s 10.33 \pm 1.36, V 8.5+1.1)$; maximum depth $357-592, \bar{x} 417.6+7.74(s 41.70+5.47, V 10.0 \pm 1.3)$; caudal (Lt - Ls) $187-339, \bar{x} 269.5 \pm 6.3$ (s $\left.34.14^{-} \pm 4.48, V 12.7 \mp 1.7\right)$.

Variation in relative size of certain regions with Ls. In part XIX (1974a) a table of dimensions of 6 individuals of $L s 52.1,161.7,182.0,185.0,200.0,221.0$ was given, and the variation in relative lengths of certain regions compared with overall length was investigated by consideration of the relevant TLS values with Ls. Comparison of the present data with data for the larger examples yields the following interesting information on relative growth.

For lengths, from tip of snout, as millesimals of $L s$, to 8 points lying in sequence caudad along antero-posterior axis of fish (end of snout, ventral origin, end of head, dorsal origin, vent, anal origin, dorsal termination, anal termination) the mean values in 6 large individuals (derivable from 1974 table) are 73.4, 79.0, 79.5, 84.1, 92.0, $91.9,99.2,99.7$ per cent of mean values (exhibited in present table) in 10 small individuals. Specimen (a) of the 1974 material stands well apart from the rest, its length being less than one-third that of the next smallest example: with this individual excluded, corresponding values for the 5 individuals are, in general, predictably somewhat smaller: $70.8,76.7,77.9,82.7,90.2,90.7,99.5,99.5$. It will be seen that, with minor exceptions (fractional deficit for vent in first set, equality of last two entries in second set), both series increase in magnitude caudad, that is, the anterior region contributes more to overall length in the juvenile than in the adult, the magnitude of the excess progressively decreasing backward. It is to be 


\section{Tasmanian Fishes}

noted differences between Ths means for 10 juveniles and 6 adults for these points are statistically significant as far back as anal origin; however, at the last two points, for which the difference of the means is only a fraction of one percent, $t$ falls below unity (not unexpectedly, in view of nornal individual variation in both series).

The resultant morphological picture can conveniently be presented thus: the percentages of standard length represented by head, trunk, tail are in the 10 juveniles $42.3,15.2,42.5$, in the 1974 material $33.6,19.3,47.0$.

For the combined 1974 sample and present material correlations of Tis values with Ls are as follows. Head $r-0.900(z 1.472), t 7.726^{* *}$, trunk $r+0.423(z 0.453)$, $t$ 1.743; tail $r+0.733$ (z 0.934), $t 4.028^{* *}$. While for trunk length the correlation is not statistically significant, it is so for length to vent $r-0.752$ ( $z \quad 0.979$ ), $t 4.275^{* *}$.

Bases of vertical fins. It has already been established that there are high correlations with Ls of length (between parallels) of Ths of dorsal base ( $p 0.964$ ) and anal base $(r 0.958)$. Values of Tls for present 10 juveniles, sma 111974 individual, other 51974 individuals are for dorsal base $396.2+8.72,421,471.0+1.96$; for anal base $237.5 \pm 7.19,245,285.6 \pm 4.68$.

Relative lengths of spines and rays. In general (dorsa1 an exception) the relative lengths (TTS) of longest spines and rays of fins for which comparative measurements are available show an increase with length of fish: however, it should be noted samples are sma 11 and dispersion is large. Mean $T Z_{s}$ values in the three groups of $10,1,5$ individuals specified above are shown below.

$\begin{array}{llccc}\text { Longest dorsal spine } & 292.7 \pm 16.0 & 344 & 280.4 \pm 7.56 \\ \text { Longest dorsal ray } & 265.1 \pm 20.2 & 378 & 604.3 \pm 76.7 \text { (4 on } 1 \text { y) } \\ \text { Longest ana } 1 \text { spine } & 146.5 \pm 4.83 & - & 163.8 \pm 6.30 & \\ \text { Longest anal ray } & 231.9 \pm 12.8 & 288 & 370.4 \pm 20.1\end{array}$

With the single 1974 specimen pooled with the rest of that material, mean value for longest dorsal spine is $291.0+11.6$, i.e., virtually identical with that for the ten sma11 individuals.

Juvenile coloration. These very young fish differ markedly in general appearance from adults, most strikingly so in the regulax presence on head and trunk of discrete, welldefined patches, usually more or less rounded, of shining silver, producing overall a conspicuous and highly characteristic color pattern.

One constant silver patch occurs below the eye, regularly occupying whole area between it and lower border of preoperculum, reaching forward to, or beyond, level of anterior border of orbit, backward to posterior preopercular border; this marking, modally subelliptical, occasionally develops at its hind end an upward extension that may fill whole space between posterior borders of orbit and preoperculum; it is constantly traversed by a rather narrow brown bar, running a little obliquely downward and backward from lowest point on orbit to lower margin of preoperculum. Other discrete, coin-like silver markings almost invariably present include one large one below pectoral base, in some instances encroaching on base, and in most individuals continuing down to ventral profile of fish; two spots, fairly large but smaller than first on trunk, 1 ying along ventral profile between that marking and anal origin: these three trunk markings about equally spaced. In some individuals additional, less conspicuous silver spots occur.

First dorsa 1 usually more or 1 ess dusky anterior $1 y$, whitish posteriorly. Second dorsal spine yellowish, somewhat dusky; first half dozen rays ranging from dark brown to black, membrane here yellowish; other rays and their membrane white. Ana 1 spines 
TABLE 4

Enoplosus armatus (White, 1790). Dimensions of ten juveniles, Low Head, northern Tasmania. First line of dimensions absolute, millimetres; other lines relative, millesimals of standard length.

$$
\text { Feature }
$$

Range

$25.4-29.1$

Standard length

Length to origin of dorsal

Length to termination of dorsal

Length to origin of anal

Length to termination of anal

Length to origin of ventral

Length of ventral

Length of pectoral

Length of caudal

Length to vent

Head

Snout

Eye

Int erorbital

Maximum depth

Depth of caudal peduncle

Length of longest dorsal spine

omitting No. 2 (430)

Length of longest dorsal ray

omitting No. 2 (450)

Length of first anal spine

Length of second anal spine

Length of third anal spine

Length of longest anal ray
$402-485$

$828-869$

$606-674$

$822-888$

$317-391$

$271-428$

$254-396$

$187-287$

$551-629$

$388-471$

$103-136$

$103-149$

$73-101$

$378-447$

$119-155$

$235-430$

$235-311$

$221-450$

$221-268$

$47-106$

$108-147$

$122-176$

$144-298$ $\bar{x}$

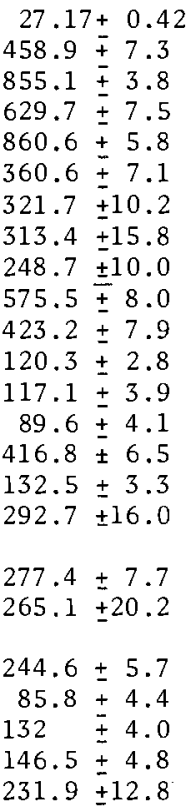

$s$

$1.33+0.297$

$23.1 \mp 5.15$

$12.1 \mp 2.70$

$23.8 \pm 5.31$

$18.2 \pm 4.08$

$22.5+5.04$

$43.1 \pm 9.63$

$50.0+11.2$

$31.6 \pm 7.06$

$25.3 \pm 5.66$

$24.9 \pm 5.56$

$8.75+1.96$

$12.3 \pm 2.74$

$12.8 \pm 2.87$

$20.4+4.57$

$10.4+2.33$

$50.6 \pm 11.2$

$23.0 \pm 5.42$

$63.7 \mp 14.3$

$17.1 \pm 4.04$

$14.0+3.12$

$12.7 \mp 2.83$

$15.3 \mp 3.42$

$40.6 \pm 9.07$
V

$5.0 \pm 1.1$

$1.4 \pm 0.32$

$3.8 \pm 0.84$

$2.1+0.47$

$6.2 \pm 1.4$

$13.4 \pm 3.0$

$16.0 \pm 3.7$

$12.7 \pm 2.9$

$4.4 \pm 0.99$

$5.9 \pm 1.3$

$7.3 \pm 1.6$

$10.5 \pm 2.4$

$14.3 \pm 3.3$

$4.9 \pm 1.1$

$7.9 \pm 1.8$

$17.3 \pm 4.0$

$8.3 \pm 2.0$

$24.0 \pm 5.8$

$7.0+1.7$

$16.3 \pm 3.7$

$9.6+2.2$

$10.0 \pm 2.4$

$17.5+4.0$ $\bar{x} \pm s$

[normal curve, 7] 
reddish yellow or whitish; rays and their membranes like those of dorsal. Pectora1 virtually colorless, faintly whitish, faintly greenish, or faintly greenish yellow. Ventral spine greenish, at times somewhat reddened; rays black or nearly so. Cauda1 colorless save for two contiguous greenish brown half-circles at hypural.

\section{Family KATSUWONIDAE}

The family Katsuwonidae, recognised as such in the Handbook (Munro 1957b, p. 114), is included by some writers (e.g., Jordan 1923, McCulloch 1929, Scott 1962) in the Thunnidae, sensu stricto ( $i . e$. , with exclusion of the mackerels), while others treat it as part of a larger assemblage, e.g., the Thunnidae, sensu Zato (Berg 1940) or the Scombridae (Greenwood et al. 1966). Of the 5 Australian species, referred to 4 genera, listed in the Handbook, 2 species, representing 2 genera, have been reported from Tasmania: Auxis thazard (Lacépède, 1802), Katsuwonus pelamis (Linné, 1758), separable by the subjoined key.

\section{KEY TO KATSUWONIDAE RECORDED FROM TASMANIA}

A. D.X-XII, 12. Dorsal fins separate; interdorsal $\rightarrow \frac{1}{2}$ head. Gill rakers on anterior arch $10-11+28-32$. Plumbeous or dark bluish above, silvery below; mackerel-like pattern of dark

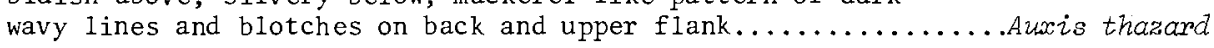

$A A$. D.XIV-XVI, 14-16. Dorsal fins joined, though in part by a mere slip of membrane that may be largely adnate to back; pseudointerdorsal, between elevated parts of fins, $<\frac{1}{4}$ head. Gill rakers on anterior arch 17-21+33-42. Uniform dark color, bluish or blackish, often with purplish and/or greenish sheen above, silvery below; about 5 dark grey longitudinal stripes along lower half of flank......................

KATSUWONUS Kishinouye, 1915

Katsuwonus Kishinouye, 1915, Sui. Gak. Ho, 1, p. 21. Orthotype, Scomber peZamis Linné. Katsuwonus pelamis (Linné, 1758).

Scomber pelamis Linné, 1758, Syst. Nat., ed. 10, p. 297. Type locality: In pelago inter Tropicos.

Example in Tamar River. Though not included in any published Tasmanian list, Katsuwonus petamis is well-known in our waters (Munro 1957 ; Scott 1962), which it visits in schools in late summer and early autumn (Robins 1952): in a schedule of fisheries for 1972-73 (Anon. 1974) Tasmania is shown as having provided 40 tonnes of the Australian total of 111 tonnes. However, it is usually taken in deep water off our East Coast. An example, Ls 482, Lt 546, caught on 10 May 1974, during the Apex Fishing Competition, in the Tamar river, between Gravelly Beach and the river mouth, provided an unusual (indeed, within the knowledge of local professional fishermen consulted, an unprecedented) record for the locality.

The specimen is also noteworthy in wholly lacking the characteristic accessory keels on the caudal peduncle.

Meristic characters. D.XV,16;8 finlets. A.14;7 finlets. P.26/26.V.I,5. C.12+12. Gili rakers on lower limb of anterior arch 37 .

Principal proportions as T2s. Length to end of upper caudal lobe II44, to end of lower lobe 1133 , to end of middle caudal rays 1050 . Length to origin, termination of first 
E.O.G. Scott

dorsa1 353, 604; of second dorsal 658, 725; of anal 701, 778. Length to vent (middle) 673. Length to origin of pectoral 303, length of $\mathrm{fin} 156$. Length to origin of ventral 313 , length of $f$ in 118 . Length to origin of upper caudal lobe 979 , to lower caudal lobe 981 ; to caudai keel 1050 , length of keel 15, height of keel 29; spread of caudal 249. Head 293; snout 54; eye 43 (horizontal diameter), 46 (vertical diameter); interorbita1 29. Oblique length of upper jaw 116. Greatest width of maxilla 20, end of maxilla to eye 23. Depth (in parentheses, width) at front of eyes 114 (83), back of eyes 147 (108), operculum 239 (160), first dorsal origin 249 (182), vent 239 (145); maximum 268 (199); caudal peduncle 24 (29). Length of first dorsal ray 81, last 15 , longest (4th) 83; first anal ray 74, last 7, longest (3rd) 80 . Ventral spine, left 98 , right 95. Lengths of dorsal spines and pelvic rays are recorded below in the section on $f$ in patterns.

Other features. Head, trunk, tail 29.5, 38.9, 31.5\%, respectively of standard length. Body-form: mesosomatic, gasterion preapical, apex median, gasterion median, mesonotic, mesogastric, leptopygidia1, opisthion preuranic (Gregory 1928).

Maxillary extending to level of front of pupi1, or 0.3 eye. Opercular membrane minutely crenulated. Teeth in jaws small, uniserial, well separated; an edentulous median space, about half eye. Pectoral reaching to below dorsal spines IX-X, ventral to below spine VII. Lateral line in part wavy, most noticeably under second dorsal, there briefly sigmoid: beyond caudal keel 15 minute projections in about $7 \mathrm{~mm}$, apparently a continuation of lateral line. Corselet extending at its main backward angle behind head by four $-\mathrm{f}$ ifths head, a superior spur continuing along lateral 1 ine by a further one-tenth head, continuous with a line of one or two scales bordering lateral line throughout most of its length; a further backward extension flanking either side of the first dorsal and most of the second. Scales of corselet decreasing regularly in height caudad from about two-fifths of an eye diameter to about one-twentieth as much. Operculum naked save for a few scales along its upper border; an elliptical naked patch at angle of preoperculum; rest of cheek scaled below a smooth pennon running back, mostly on dorsum, from near upper orbital rim to within about one and a half eye diameters of dorsal origin, scales, many large, polygonal or longitudinally subelliptical, extending down from this to inferior border of preoperculum, and continuing forward below eye to level of end of gape. Main ventral keel well developed (dimensions above); no accessory keels. Dorsal wholly retractable into a slot, from which a pull on the anterior spine brings it out like a half-opened fan. Anal set on a subelliptical escutcheon, its minor (transverse) axis one-third its major axis, or about two-thirds eye. A similar, slightly wider, but less conspicuous elevated area surrounding base of second dorsal.

Coloration. General color bluish silvery above lateral line, chiefly silvery below it. Five well-marked dark stripes on flank below lateral line, the longest extending from shortly behind pectoral almost to caudal peduncle; widest above anal base, width of lower two here subequal to interval between them, others wider than their interspaces. Larger scales on trunk usually outlined in, smaller usually spotted with, dirty white. Large scales on cheek dark grey, outlined in greenish gold or whitish. Small black spot at upper end of opercular border. Internal surface of pectoral base"with one (right side) or two (left) black arcs; both fins with subelliptical blackish spot at base of upper rays. Dorsal spines mainly slaty with some darker patches; membrane greyish, with, from about 6th interval backward, increasing blackish smudging, most pronounced distally. Second dorsal tolerably even grey; some small patches, approaching black, at tips of first few rays. Anal grey. Dorsal and anal finlets slaty, with whitish border, wider, more sharply delimited in anal. Pectoral greyish. Ventral somewhat yellowish grey, some duskiness in preaxial half or so. Caudal mainly greyish with some dusky clouding, hind border briefly almost white.

Remarks. Surprisingly, the specimen presents no indications of the presence of the characteristic smaller keels normally found (Munro 1958b, p. 114) above and below the 


\section{Tasmanian Fishes}

primary keel on either side of the caudal peduncle. In general form and color pattern it agrees closely with the figure by Serventy (1941, p1. 3, fig. 2). The Flandbook notes two proportions only: these (with our values in parentheses) are depth 3.7-3.8 (3.74), head 3.1-3.4 (3.40) in length without cauda1.

Disposition of finlets. The 8 dorsal and 7 anal (ventral) finlets are divisible in respect of their relative locations, into an anterior subset of 3 in either fin and a posterior subset of 5 (dorsal), 4 (anal). With distance from tip of snout to first finlet measured between parallels, and with intervals between finlets measured directly with callipers, the following relations are found ( $L=$ length to finlet origin, $N=$ serial number of finlet, counting caudad). For dorsal finlets 1-3 the best straight line is $\log L=0.1000 \log N+2.5600 \quad(t=9.022)$, giving measured (predicted) lengths, mm, $364.0(363.5), 386.5(385.1), 407.0(405.2)$; for ana $11-3 \log L=0.07544 \log N+2.5869$ $(t=9.409)$, with lengths $387.0(386.3), 405.0(407.0), 421.0(419.7)$. For dorsal finlets $4-8 \log L=0.1625 \log N+2.5262$ ( $t=40.505)$, with lengths 421.4 (420.7), 435.5 (436.2), 448.6 (449.6), 461.4 (460.8), 471.7 (470.9); for anal $4-7 \log L=0.1519 \log N+2.5445$ $(t=24.681)$, with lengths $436.0(437.2), 450.5(447.4), 465.0(460.0), 474.0(470.9)$.

Fin patterns. In species, belonging to various families, so far examined the most common type of dorsal fin presents an anterior suite of spines increasing in length caudad, followed by a (usually longer) suite decreasing in length caudad - the latter not infrequently resolvable into two or more components, the graphs of which, with log length plotted against log inverse serial number ( $i . e .$, spines counted cephalad), exhibit a positive slope. Here the fin not only represents a less common type in that the most anterior spine is the longest, but it presents a further unusual feature, the plotting of $\log$ length against log serial number (direct or inverse as appropriate) yielding linear graphs for three subsets as follows: $(\alpha)$ on serial numbers $1,2,3$ spines III, II, I (slope positive); (b) on serial numbers 1, 2, 3 spines IV, V, VI (slope negative); (c) on serial numbers $1-9$ spines XV-VII [spine IX on 7 omitted; imperfect] (slope positive) - subset (b) thus being of an exceptional character. Specifications of these three subsets are as follows: $(\alpha) \log L=0.2099 \log N+1.7877$; measured (predicted) lengths, mm 61.3 (61.3), $71.0(70.9), 77.2(77.2) ; t=19.834:$ (b) $\log L=-0.7547 \log N+0.6552 ; 44.9(45.2), 27.3(26.8) .19 .5(19.7) ; t=25.164:(c) 10 g$ $L=0.2353 \log N^{1}+0.9130 ; 8.0(8.2), 10.0(9.6), 11.0(11.3), 12.0(12.0), 12.1(12.5),-$ $(-), 13.3(13.4), 14.0(14.7) ; t=17.341$ (with more material available for examination, it is possible (c) might be divisible into anterior and posterior sections).

Equations of the form $L=b N^{k}$, here presented as $\log L=k \log N+\log b$, are noted below for pectoral rays $1-4$. For left fin $k$ is 0.7150 , for right 0.7401 ; $\log b$ for left 1.2650, for right 1.2367; significance, left $t=43.256$, right $t=17.216$; measured (calculated) lengths, mm, left 18.4 (18.4),30.0 (30.2),41.2 (40.4), 49.0 (49.6), right $17.4(17.2), 28.1(28.8), 39.3(38.9), 48.4(48.1)$. No simple and obvious relationship between on the one hand the subset of rays 1-4 and on the other hand ray 5 and spine is apparent. However, when $\log$ lengths of ray 1 , spine, ray 5 are plotted on 1 ogs, 1, 5, 6 , respectively, a virtually linear graph results - a formulation perhaps, however, without systematic significance. For left ventral $\log L=0.5925 \log N+1.2642$; lengths 18.4 (18.4), 47.0 (47.7), 53.8 (53.1); $t=136.39$ : for right $\log L=0.6084 \log N+1.2410$; $17.4(17.4), 46.0(46.4), 52.3(51.8) ; t=12.988$.

\section{Family BOTHIDAE}

Tasmanian members of the family listed in the Handbook (Munro 1957b) comprise (a) Lophonectes gallus Gunther, 1860, (b) Amoglossus muelleri (Klunzinger, 1872), (c) A. bassensis Norman, 1926, (d) A. andrewsi Kurth, 1954 (endemic), (e) Pseudorhombus tenuirastrum (Waite, 1899), $(f)$ P. jenynsii (Bleeker, 1855). None of these appear in either of the local lists of Johnston $(1883,1891)$. Lord $(1923,1927)$ and "Lord \& Scott (1924) list (a) and (e), together with $(g)$, Pseudorhombus muztimaculatus Gunther; while the Australian Checklist (McCulloch 1929) records as Tasmanian $(a),(b),(c),(d)$, accept- 


\section{E.0.G. Scott}

ing $(g)$ as a valid species, but not accrediting it to this state. Norman, having treated the Small-toothed Flounder under Gunther's name, $(g)$, in his report on the Endeavour Heterosomata, later in his monograph (1934) referred it to the synonymy of $(f)$, a course in which he is followed by Munro in the Handbook.

A new species of Arnoglossus Bleeker, 1862 is here described and figured, and some observations are made on two examples, a male and a female, of Lophonectes gallus. A key to the Tasmanian species is subjoined.

Genus LOPHONECTES Güther, 1880

Lophonectes G̈̈nther, 1880, Rept Challenger, Zool., 1(6), p. 28. Haplotype, Lophonectes gallus Gunther.

Lophorhombus Macleay, 1883, Proc. Linn. Soc. N.S.W., 7 (1), „p. 14. Haplotype, Lophorhombus cristatus Macleay = Lophonectes galtus Gunther.

Lophonectes gallus Günther, 1880

Lophonectes gallus Güther, 1880, Rept Challenger, Zool., 1(6), p. 29, p1. XV, fig. B. Type locality; off Port Jackson; $30 \mathrm{fms}$.

Laeops parviceps Gunther, 1880, Rept Challenger, Zool., 1(6), p. 29; partim (2 Challenger specimens, off Twofold Bay, N.S.W., $120 \mathrm{fms}=$ young).

Lophorhombus cristatus Macleay, Proc. Linn. Soc. N.S.W., 7 (1), p. I4. Type locality: Port Jackson.

Distribution. All Australian States except Western Australia; also, if L. monoguiensis Regan, 1914 is conspecific [so regarded by Norman (1934, p. 202), but accorded specific status by Whitley (1968, p. 47)], New Zealand. It does not appear in either of the Tasmanian lists of Johnston $(1883,1891)$, while in those of Lord $(1923, p .65 ; 1927, p .13)$ and Lord \& Scott (1924, p. 47) the entry is merely the name, unaccompanied by locality records or other data. Some observations are here made on two specimens, $(a) f e m a l e$, Ls 116, Lt 142, (b) male, Ls 119, Lt 145, collected 24 August 1973 off Prime Seal Island, Furneaux Group, Bass Strait by Mr P. Armstrong; Q.V.M. Reg. No. 1974/5/53.

General features. In the subjoined description features are noted in the same order as in the description in Norman's monograph (1934, p. 202, fig. 150) based on 28 examples from New South Wales, Bass Strait, and off the northern is land of New Zealand, quantitative data reported by him being here cited in parentheses: however, some additional items are intercalated at appropriate points. Where a datum is reported twice the first entry relates to the smaller individual (female).

Depth 2.6 (about $2 \frac{1}{2}$ ), depth at front of eyes $7.0,6.8$, at back of eyes $3.7,4.2$,

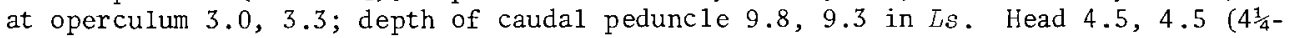
$5 \mathrm{I} / 5$ ) in Ls. Snout $1.2,1.3$ in lower eye, $1.3,1.3$ in upper eye (shorter than eye). Eye, Iower, $3.8,3.5$, upper $3.8,3.3\left(3 \frac{1}{4}-4\right)$ in head. Eyes separated by a narrow bony ridge, lower $0.3,0.2$ its own diameter, (very slightly) in advance of upper, which is separated from edge of head by a space equal to $0.4,0.4\left(1 / 5-\frac{1}{2}\right)$ its diameter. Interorbita1 7.1, 8.0 in diameter of lower eye, direct distance between middle of upper border of upper eye and middle of lower border of lower eye 1.6, I.4 diameter of lower eye. Maxillary extending to below middle of elevated fleshy orbital rim, short of rim by width of rim (below anterior edge or a little beyond); its length $3.8,3.8$ (3 1/3nearly 4$)$ in head; lower jaw $2.2,2.2\left(2 \frac{1}{4}-22 / 3\right)$ in head. Both nasal organs on ocular side, the larger more advanced one lying on horizontal level of interorbital, its distance from mouth cleft subequal to its height, or about half its distance from lower eye, which is a little less than its distance from upper eye; whitish, unpigmented save for very brief basal peppering of minute brownish chromatophores; elliptical in plan, set obliquely, erect; pentagonal posterior wall three or four times as high as anterior 


\section{KEY TO BOTHIDAE RECORDED FROM TASMANIA}

1. Lateral line on both sides; that on ocular side extending in advance of upper end of operculum in an upward supratemporal branch reaching to dorsal base, and in a downward branch behind eyes. Bases of left and right ventrals subequal; subequal to anal-ventral interspace. D. 84

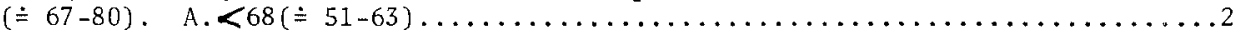

Lateral line on ocular side only; terminating close to upper end of operculum. Base of left ventral much longer than base of right; greater than anal-ventral interspace. D. $84(\doteq 87-99)$. A.> $68(\doteq 71-78) \ldots \ldots \ldots \ldots \ldots \ldots \ldots \ldots \ldots$

2. Scales ctenoid on ocular side, cycloid on blind side. Gill rakers on lower part of anterior arch 6-10. Head 3 2/5-4 (nearly) in LS. D. 67-74. Markings include 5 ocelli, in 2 pairs, one member of each pair above the other, and a (posterior) azygous ocellus (exceptionally,

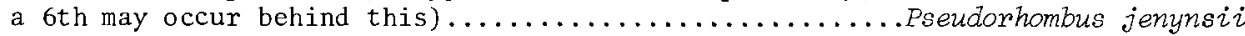

Scales cycloid on both sides (those on ocular side often with rough or spiny patch well within hind margin of scale). Gill rakers on lower part of anterior arch

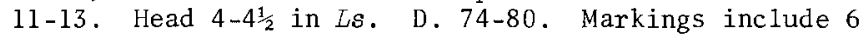
ocelli, in 3 pairs, one member of each pair above the

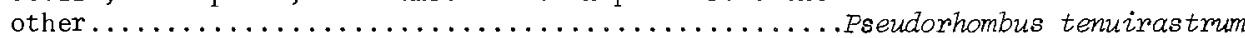

3. Some anterior dorsal rays produced. Maxillary $3 \frac{1}{4}-4$ in head. Male with bony tubercles on snout and near mandibular symphysis; these smaller, blunter, occasionally absent, in female........................... tophonectes gazzus No dorsal rays produced. Maxillary $2-3$ in head. No bony tubercles on snout or near mandibular symphysis $\ldots \ldots \ldots \ldots \ldots \ldots \ldots \ldots \ldots \ldots \ldots$

4. Gill rakers pointed, simple .............................

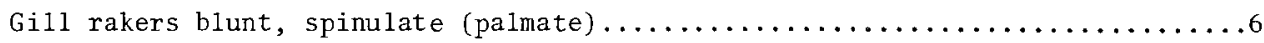

5. Scales ctenoid (feebly) on ocular side, cycloid on blind side. Lateral line scales $<80(\doteq 68-73)$. A.72-75. Body

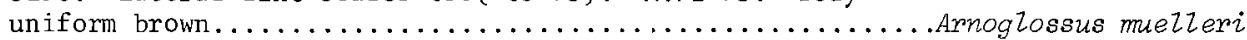

Scales cycloid on both sides. Lateral line scales $>80$ $(\doteq 87-92)$. A.77-78. Body greyish brown, with dark blotches and spots, including two large black blotches on lateral

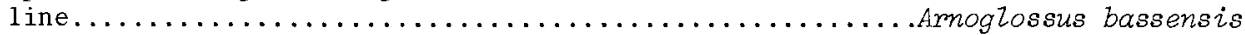

6. Anterior dorsal profile normally rounded, reaching apex about a head length behind head, then descending evenly to caudal peduncle. Both sides of dorsal and anal rays scaled. Left P.10. D.90-94. Caudal rounded.............Arnoglossus andrewsi Anterior dorsal profile rising steeply, reaching apex about above opercular border, then continuing backward virtually horizontally for about one and a half head lengths before descending evenly to caudal peduncle. Only ocular side of dorsal and anal rays scaled. Left P.12. D.98. Caudal obtusely pointed....................nnoglossus armstrongi 


\section{E.O.G. Scott}

tubular wa11, which is lowest mesially, curving up laterally to meet elevated hind wa1l; two digitiform processes, one higher, arising from middle of posterior wall, one from middle of anterior wall; nasal laminae apparently with a central rachis: the hinder organ contiguous basally with the front one, behind and partly below it; concolorous with snout nearby; a rounded or slightly elliptical mound, lower wall steeper than upper; a terminal crescentic opening, its long axis sloping about equally downward and forward. Margins of operculum and preoperculum entire; free hinder border of preoperculum extending up to 1 evel of lower half, just above middle, of pectoral base. In both specimens two largish ocular and several rudimentary rostral tubercles on ocular side, one large complex one just behind mandibular symphysis; bony, enveloped, except, usually, at tip, in thick integument.

Teeth present on both sides, perhaps a little better developed on blind side, sma11, slender, uniserial, those in front half of jaw somewhat larger than those behind them (teeth smal1, scarcely enlarged anteriorly). Gill rakers moderate, longest about half longest gill filament, 6 on lower limb of anterior arch, increasing in height and width from 1st (uppermost) to 4th, with 5th, 6th lower, wider, subequal; earlier about twice, later about one and one-third as high as wide (short or of moderate length, rather stout; 6 or 7 on lower part of anterior arch). Scales on ocular side ctenoid, moda1ly with 20-22 slender, acuminate spinules, their length from once to about twice, modally about one and a half, their interspaces (ctenoid): on blind side cycloid, exposed margin evenly rounded or somewhat sinuate (cycloid). Scales on lateral line 67 [ 2 on caudal], 69 [ 4 on caudal] $(62-70)$. General course of lateral line much as in Norman's illustration (fig. 50) with the following modifications: female, short anterior segment longer, with about 6 tubules, descending almost to operculum, with a terminal upwardly concave portion of 2 tubules; male, anterior segment of 5 descending at a lesser angle, with the first tubule not far from horizontal, and at junction of its 2 uppermost tubules what appears to be an abnormal accessory branch running backwards and downwards over 2 scales, then bifurcating and continuing for rather more than another scale. Width of curved portion of lateral line, measured horizontally at lower end of subvertical portion of anterior segment [i.e., 3 tubules down this line in (a), 1 tubule in (b)] $2.7,2.4$ in head. Lateral line not developed on blind side.

Dorsal $88,88(87-93)$ rays simple; in (a), female, 1 st-7th rays $0.23,1.27,1.20$, $1.06,0.42,0.42,0.42$ head (only the third to fourth or fifth rays prolonged in the female, length $\frac{1}{2}$ to $9 / 10$ that of head) ; in (b), male, 1 st -7 th rays $0.23,1.28,1.08$, $1.35,1.26,0.72,0.42$ head (second (occasionally first) to fifth, sixth or seventh rays much prolonged in the male (except in very young), longest rays (in adults) $1_{i}^{\mathrm{I}_{i}}$ to about twice length of head); in (a) last ray 0.08 , ray at middle of fin 0.44 head, in (b) $0.08,0.46$ : ocular side of rays with minute, deeply embedded scales along most of their length, the best developed with about 10-12; blind side of rays without scales. Anal 70,75 (71-77), rays simple; 1st ray $4.0-$ [imperfect], 2nd $3.3,3.3$, ray at middle of fin $2.3,2.2,1$ ast ray $2.7,2.4$ in head; ocular side of rays with up to a score of minute deeply embedded scales along most of their length. Pectoral of ocular side 12, 12 (11-12), rays simple, length, whole fin, $0.8,0.8$, longest [ $3 \mathrm{rd}, 3 \mathrm{rd}=4$ th] ray $0.7,0.7$ head (pectoral length $2 / 3-3 / 4$ head). Pectoral of blind side, 11 , 11 , rays simple, about two-thirds size of that of ocular side, length, whole fin, $0.6,0.5$, longest ray [ 5 th, 4 th $=5 \mathrm{th}$ ] $0.5,0.4$ head. Left ventral 6,7 [ 7 th, posterior, rudimentary], rays simple, longest ray [3rd, 3rd] $0.4,0.4$ base, measured from ray to ray, $0.3,0.4$, or, including posterior membrane $0.4,0.4$ head; adpressed, fin reaches just short of level of posterior angle of operculum, below origin of pectoral base, anterior portion of base extending somewhat in advance of lower angle of operculum, set on, or virtually on, midventral line, posterior portion swinging slightly on to 1 eft flank. Right ventral 6, 6, rays simple, longest ray [4th, 4th] $0.3,0.3$ head, base 1 ess than half that of left ventral [0.2, 0.1 head], originating about opposite middle of right base, terminating briefly before it, lacking posterior attachment membrane, wholly off midventral line, set somewhat obliquely, posterior end about twice as far from median 1ine as anterior end. Caudal 17, 18, with 11,10 rays divided, pointed in male, rather 
more rounded in female, longest ray $1.0,1.1$ in head; scales extending well up rays on ocular side, confined to about basal one-seventh on blind side; some small hairlike processes on proximal half of rays on ocular side.

General color, after preservation, of ocular side somewhat brownish grey, appearing yellowish where scales have been lost; of blind side more or less uniform pale yellowish, except for some pale orange in an ill-defined patch on head, and in strips along dorsal and ventral profiles demarcating location of pterygiophores; no obvious discrete markings on either side. Dorsal and anal rays greyish, mostly with smal 1 brownish dots, spaced like the scales; membranes pale grey. Pectoral of ocular side grey; in (b) a regular arc of small brown spots between bases of rays, indications of two or three further irregular arcs in proximal one-third of $f$ in; in (a) spots fewer, more irregularly disposed; in both specimens some similar spots on fin base. Pectoral of blind side white. Ventral of ocular side with anterior rays and membrane between them wholly or mostly white or whitish, other rays conspicuously dusky, in part almost black, tips of rays white. Ventral of blind side white. Caudal more or less colorless, rays a little dusky distally in female.

Remarks. From the above comparative account it can be seen our specimens agree closely with Norman's description, with fin counts and body proportions falling in all cases

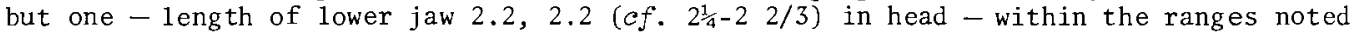
by him. Perhaps the most noteworthy differences are the more pointed caudal in the male in our material, and the presence (probably abnomnal and individual) in the same fish of an accessory branch arising from near the anterior end of the lateral line.

Lophonectes galzus appears to provide yet another example of a species found in New South Wales [a1so, in this instance, in Queensland (Marsha11 1964)] occurring in Tasmania without appearing in South Australia (or ? Victoria).

In his report on the Thetis expedition - which found this species the commonest flatfish secured -,Waite (1899, p. 124) called attention to the comment by Ogilby (1886 p. 48) on Gunther's (1880) original figure, based on ChazZenger materia1, 'ln Dr. Gunther's figure the fish is coloured on the wrong side, the short first dorsal ray is omitted, and there is a separation between the elongated and short rays of that fin which is purely imaginary.'

Additional material. Since the above observations were made, an additional example has come to hand, this time from the other (western) side of the north coast region, a male, Ls 119.0, Lt 143.0, dredged in Ringarooma Bay by Mr J. Shea on 19 September 1974; Q.V.M. Reg. No. $1974 / 5 / 167$.

D. 88, A. 76. P., ocular side 12, its length 1.6; blind side 10, its length 1.8 in head. Both ventrals 6; longest ray of left (4th) 2.24 , of right (4th) 3.2 in head; base of left 2.7 , of right 5.4 in head. C. 3+11+3. Depth 2.7, head 4.4 in Ls. Snout 1.2 in upper, 1.3 in lower eye, latter 3.9 in head (a11 eyeball measurements), or 1.9 , $1.7,2.9$ (total eye). Maxilla to front of eye; lower eye in advance of upper by almost one-third diameter of its eyeball ('slightly', Norman 1934). Maxilla 4.0, lower jaw 2.3 in head, Produced dorsal rays 2 nd, 3 rd (longest 1.18 head), 4 th, 5th. Dorsal lst, middle, last rays 4.4, 2.1, 9.3 in head; ana $13.1,2.3,13.6$ in head. Depth of caudal peduncle $2.17 \mathrm{in} \mathrm{head.} \mathrm{Characteristic} \mathrm{dark} \mathrm{distal} \mathrm{marking} \mathrm{on} \mathrm{left} \mathrm{ventral,} \mathrm{involving}$ rays 3-6, darkest, almost black on 3 rd ray.

Genus ARNOGLOSSUS Bleeker, 1862

Arnoglossus Bleeker, 1862, Verst. Med. K. Akad. Wet. Amsterdam, 13, p. 427. Tautotype, Pleuronectes arnoglossus Bloch \& Schneider.

Amoglossus Norman, 1934, Monogr. Flatfishes (Heterosomata), 1, Psettodidae, Bothidae, Pleuronectidae, p. 173 (synonymy). 
Arnogiossus armstrongi sp. nov.

(fig. 2)

Diagnosis. Anterior dorsal profile rising very steeply, reaching its virtual apex about above opercular border, then continuing back almost horizontally for about one and a half head lengths. Depth 2.2 , head 3.8 in length without cauda1. Barely notched in front of eyes, but decidedly concave here. Scales ctenoid on ocular side, cycloid on blind side. D.98. A.74; rays with scales on ocular, not on blind side. P.12/12. Latera1 line on left side only; curved over pectoral, no supratemporal branch. Gill rakers 1 ow, broad, partly spinulate ('pa1mate').

Size. Standard length, Ls, 168.5, total length, Lt, 198.5 .

Meristic characters. D.98. A.74. V.6/6. P.12/12. C.17 (3 upper, 2, ?3, 1ower, rays simple). Lateral line tubules 91 (22 in anterior curved segment, 58 in horizontal segment to hypural, 11, becoming progressively smaller, on caudal).

Principal dimensions. Measurements are given as Tls, with absolute dimensions, $\mathrm{mm}$, in parentheses. Head 261 (43.9). Snout to orbit 53 (9.0), to eyebal1 58 (9.8). Upper eye, eyebal1 $53(9.0)$, total $62(10.5)$; 1 lower eye, eyebal1 $51(8.6)$, total $64(10.7)$. Interorbital 7.1 (1.2). Length of maxilla 100 (169), of lower jaw 131 (22.0). Length to vent (middle) 236 (39.7), diameter of vent 21 (3.6). Depth at front of eyes 154 (26.0), back of eyes $249(42.0)$, vent 374 (63.0), opercular border 389 (65.5); maximum depth $416(70.0)$; depth of caudal peduncle 107 (18.1). Lengths of dorsal rays, 1 st 53 (9.0), middle 118 (19.8), last 18 (3.0); of anal rays, 1st $62(10.4)$, middle $125(21.0)$, last $12(2.0)$. Left pectora 1 , length $137(23.0)$, longest $(3 \mathrm{rd}=4$ th) ray $127(21.4)$, oblique length of base 35 (5.8): right pectoral, length 119 (20.1), longest (6th) ray $118(19.8)$, oblique length of base $21(3.5)$. Left ventral, base $77(12.9)$, longest (5th) ray $65(11.0)$ : right ventra1, base $41(6.9)$, longest (3rd) ray $48(8.1)$.

General description. Dorsal profile fairly evenly rounded from mouth cleft to level of middle of eye, barely notched; excavated in front of rest of eye and for about half an eye diameter above it; thereafter rising in a compound segment with chord about equal to head without eye, to reach within a millemetre or two of greatest height of whole dorsal profile at level of opercular margin, this segment with its anterior half almost straight, at approximately $40^{\circ}$ to horizontal, the rest moderately convex; behind operculum profile nearly straight (height of chord about one-third eye) to $0.7 \mathrm{Ls}$, or behind head by 1.6 head; thence in one gently sigmoid sweep, its general sense approximately $30^{\circ}$ to horizontal, to caudal base. In ventral profile lower jaw straight; a slight spur at its junction with moderately rounded operculum; thence one convex sweep, with increasing ly rapid curvature caudad, to caudal base; lowest point behind head by about two-thirds head. Depth at front of eyes 6.5 , behind eyes 4.0 , at vent 2.7 , at opercular border 2.6; maximum depth, found at one-third of 1 ength, 2.4; depth of caudal peduncle 9.3 in Ls.

Head 3.84 in Ls. Snout a little shorter than full eye; measured to orbit, equal to upper eyebal1, 1.05 lower. Lower eye in advance of upper eye by about one-sixth diameter of latter; lower closer to maxilla than upper to dorsal profile. Upper eye, ful1, eyebal1 4.2, 4.9 in head; lower 4.1, 5.1: separated by a narrow bony interorbital, on to the posterior one-third of which closely-set scales extend, the rest naked; from scales the median ridge on which they are set continues forward as a well-elevated, translucent, somewhat porcelain-like bar, following the curve of the lower eye, and constituting, in effect, its supraorbital ridge, its distance from the other eye thus being greater at its ends (especially the anterior) than at its middle; least width of interorbital about one-seventh diameter of lower eyeball. Maxilla extending to below 0.3 lower orbit; hind margin obliquely truncate, with lower, rounded angle projecting behind upper; length 2.6 in head, or 4.2 its greatest width measured normal to its main axis. Lower jaw 2.0 in head: with mouth closed, lower lip slightly in advance of upper; 
a small tubercle near mandibular symphysis a little further advanced. Teeth at back of jaw minute, at front usually large, stout, more or less strongly recurved; bulk of largest greater than that of smallest by a factor probably exceeding fifty; on 1eft side 8 in upper jaw ( 3 large, 1 medium), 9 in lower jaw ( 3 large, 2 medium); on right side 15 in upper jaw ( 5 medium-small), 10 in lower jaw; in general uniserial, but a couple of pairs; characteristically, well, or fairly well, separated, but one set of 4 small set very close together; some of the larger teeth apparently depressible. Gill rakers on lower limb of hinder arch 6, 'palmate' (i.e., short broad, margins spinulate; Norman), variable in form; 1st (uppermost) a digitiform process, sloping slightly downwards, spinulate at tip and on upper border; 2nd a smaller, more rounded, more sloping process, delicately crenulate distally; 3rd subtriangular, similarly crenulate; 4th and 5 th with longer bases, more rounded, somewhat more boldly crenulate (especially $4 \mathrm{th})$; 6th little more than a low crenulated ridge, its length about one and one-third that of 5th, about 4-5 times its own height. On lower limb of anterior arch 5 (?) rakers, apparently more or less similar to, but less developed than, those on hind arch. A small set of long acute pharyngeal spines. Lateral line comprises (a) a principal midlateral segment of 58 tubules curving upward from middle of caudal peduncle to a point behind head by about combined eye and snout, 1.4 times as far from ventral as from dorsal profile, overlapped here by distal one-fourth of adpressed pectoral, the curve roughly divisible into two sections, anterior about twice as long as posterior, height of overall curve about half an eye diameter; (b) anterior segment curving over pectoral, in region of nape, made up, proceeding cephalad, of an upward and forward series of 5 tubules, a longitudinal series, moderately curved upwards, of 9 , a downward and forward series of 5 with a forward more or less horizontal spur of 3 , ending shortly above, just in advance of, upper angle of operculum, width of curved portion, without spur, 1.3 in head; (c) a series of 11 tubules on caudal, becoming progressively smaller, only first 2 or 3 comparable in size with those on flank.

Vent on blind side above base of 1st anal ray; length to middle 4.22 in $L s$, or 0.90 head.

Dorsal with 98 rays, none prolonged, all simple; scaled on ocular, not on blind side; 1st ray inserted on blind side (and exhibiting its coloration, white; $c f$. other rays, dark grey), insertion behind snout profile by about half its distance from upper lip, or one-third length of ray, which is 4.9 in head; middle rays 2.2 in head; last ray briefly in advance of $1 \mathrm{st}$ caudal ray, 14.5 in head. Anal with 74 rays, all simple; scaled on ocular, not on blind side; lengths of 1st, middle, last rays 4.2, 2.1, 22.0 in head; last ray inserted in advance of caudal by about its own length. Both ventrals with 6 simple rays; base of left 1.9 that of right, or 3.4 in head; longest ray of left 1.4 that of right, or 4.0 in head. Both pectorals with 12 simple rays; left 1.1 length of right, or 1.9 in head, its base 1.7 base of right, or 7.5 in head. Caudal with 17 rays, of which 3 upper and 2, ?3, lower are simple; obtusely pointed.

Coloration. In its present state, after preservation, the greater part of the ocular side of the fish has an almost uniform pale yellowish ground color; each scale pocket (most scales lost) outlined in blackish, resulting in an overall dark lattice. Some areas with ground color a little dusky include ovoid abdominal region, a longitudinal strip a little more than an eye diameter in width extending subparallel to ventral profile from end of abdomen to within about a head length of hypural, its distance from profile subequal to its width, an indefinite narrow dusky strip along most of dorsal profile, a slight and obscure mesial darkening on flank in posterior one-fourth of length, and much of snout. The only conspicuous marking is a short upright irregular blackish bar lying across lateral line at end of second third of length of its main segment, its width about half its height, latter rather more than an eye diameter. Blind side virtually uniform pale yellowish, devoid of any noticeable marking.

Ocular side of dorsal rays ranging from light to dark grey, most with a more or less well developed series of up to a dozen darker spots or patches indicative of 


\section{E.O.G. Scott}

position of scales; blind side of rays chiefly whitish or very pale greyish, some showing slight distal duskiness; first ray wholly white. Anal rays in general similar to dorsa1; some anterior ones more distinctly white on right side. Left pectoral dark brownish, with some short blackish bars, several forming an arc; right wholly white. Rays of left ventral like those of left side of anal rays; of right ventral white.

Materia1. Described and figured (fig. 2) from the unique holotype, standard length $\overline{168.5 \mathrm{~mm}}$, tota1 1ength 198.5, collected at Bridport, northern Tasmania, on 15 August 1973 by Mr Philip Armstrong, in whose honour the species is named; deposited in the Queen Victoria Museum, Launceston; Reg. No. Q.V.M. 1974/5/168.

The specimen is not in a particularly good state of preservation, apparently having been subject at some stage to desiccation that has led to loss of most of membrane of vertical fins and to marked brittleness in most of their rays. It is not feasible to determine with certainty throughout the full lengths of dorsal and anal just how far up the rays the membrane originally extended (a point not without taxonomic significance: contrast, for example, the short membrane between early dorsal rays in $A$. bassensis with the almost ful1-length membrane in $A$. andrewsi). There are some indications that suggest the early dorsal membrane may here not have extended to near the tip of the ray.

Affinities. The holotype differs at sight in general form from all described species of Arnogtossus (to which genus, however, it appears clearly to belong), the long section of virtually straight upper profile behind head being somewhat suggestive of a dextral soleid. As only a single example is available, the possibility that this unusual shape is an individual variation cannot wholly be ruled out: however, additional diagnostic features serve adequately to characterize the species. Of the nine species of Arnoglossus Bleeker, 1862 appearing in the Handbook (Munro 1957b) four have scales of both sides cycloid, and henfe call for no consideration here. From the remaining species [including $A$. tenuis Gunther, 1880, for which no characterization of scales is noted in the Handbook, but which has scales on ocular side feebly ctenoid (Noman 1934, p. 188)] the present form is distinguishable as below.

From A. błeekeri Macleay, 1882 (referred, somwhat provisionally, by Norman to Engyprosopon Gunther, 1862 on dentition) by that species' dentition (partly biserial), interorbital (groove), gi11 rakers (not palmate), fewer dorsal rays (90-93), fewer lateral line scales (50), smaller head (4.2-4.5 in Ls), shape of caudal (rounded), color pattern (spot on operculum).

From A. muelzeri (Klunzinger, 1872) by that species' gill rakers (not palmate), more numerous latera 1 line scales $(68-73$, i.e., from near angle of gill opening to caudal base), fewer pectoral rays (10), smaller head (4-4.5 in Ls), shape of caudal (rounded), probably color pattern (fins with small brown spots).

From A. intermedius (B1eeker, 1866) by that species' interorbital (groove), fewer dorsa 1 rays $(77-82)$, fewer ana 1 rays $(57-62)$, fewer latera 1 ine scales (43-46), shape of caudal (rhomboidal), color pattern (dark blotches and annular markings on body, all fins with numerous dark spots).

From A. tenuis Günther, 1880 by that species' dentition (teeth all sma11), gil1 rakers (not palmate), fewer dorsal rays (90-93), fewer anal rays (70), fewer lateral line scales (48), possibly smaller head [given by Norman (1934, p. 187) as 4-4.5; in Handbook, apparent1y in error, 2.75].

From A, andrewsi Kurth, 1954 by that species' fewer dorsal rays (90-94) fewer pectoral rays (10), scalation on dorsal and anal rays (on both ocular and blind sides of both fins), possibly by smaller head [Kurth (1954, p. 46), noting head in Ls for holotype as 4.2, gives range as 2.4-4.4 (figures repeated in Handbook): a figure of 2.4 


\section{Tasmanian Fishes}

would seem to indicate an improbably large head: for five species with head in Ls about 4 the ranges given in Handbook 1 ie between 0.25 and 0.5 : possibly 2.4 is misprint for 4.2].

of the five species just noted only two A. muelleri and A. andrewsi are recorded from Tasmania (latter endemic), the others being Queensland forms. On the whole, the present species comes closest to $A$. andrewsi, with which it shares the unusual possession of palmate gill rakers. The character would appear to be an important one. Of 24 species of Amoglossus recognised by him, Noman observes $(1934, \mathrm{p} .198$ ) of A. intermedius, 'This species is provisionally placed here, but perhaps represents a distinct genus. It may be distinguished from all species of Amogrossus by the form of the gill-rakers [palmate], which are similar to those of certain species of Pseudorhombus, and from most of them by the concave interorbital space'; and in his synopsis of 24 species of Pseudorhombus he keys off those 3 species $-P$. spinosus McCu11och, 1914, $P$. diplosus Norman, 1926, P. dupliciocellatus Regan, 1905 (all reported from Australia) - that have the gill rakers short, broad, spinulate.

\section{Family SOLEIDAE}

Of the two families of soles that have generally been recognised, and that are accepted by Greenwood et al., the dextral soles, or true soles, Soleidae, and the sinistral soles, Cynoglossidae, with, respectively, 27, 11 Australian species (Munro $1957 \mathrm{c}$, d), the former has hitherto been without known Tasmanian representatives, while the latter provides one entry in the local list, Paraplagusia unicolor (Macleay, 1881). The second family noted above is subsumed in the first by Weber \& de Beaufort (1929), while the Australian Checklist (McCulloch 1929) separates off from the second family, a third, Synapturidae.

Two examples of Zebrias fasciata (Macleay, 1882) are here reported from our waters.

Genus ZEBRIAS Jordan \& Snyder, 1890

Zebrias Jordan \& Snyder, 1890, Froc. U.S. Nat. Mus., 23, p. 38. Orthotype, SoZea zebrias Temminck \& Schlegel.

\section{Zebrias fasciata (Macleay, 1882)}

Synaptura fasciata Macleay, 1882, Proc. Linn. Soc. N.S.W., 7(1), p. 14. Type 1ocality: Port Jackson.

Synaptura fasciata Waite, 1899, Mem. Aust. Mus., 4(1), pl. XXXI. Id. McCulloch, 1916, Mem. Qld Mus., 5, p. 61, pl.VIII, fig. 2. Id. McCulloch, 1929, Mem. Aust. Mus., 5 (2), p. 285 .

Brachims fasciatus Norman, 1926, Biol. Res. Endeavour, 5(5), p. 295.

Zebrias fasciatus Munro, 1957, Handbk Aust. Fish., 17, p. 71, fig. 494.

Record. Two examples collected by Mr P. Armstrong, (a) Ls 131, Lt 149, between East Sandy Cape and Thirty Day Island, 1973 (received 9 August), Q.V.M. Reg. No. 1973/5/104; (b) Ls 96, Lt 109, off Prime Seal Island, Furneaux Grcup, Bass Strait, 24 August 1973, Q.V.M. Reg. No. 1974/5/38. First Tasmanian record: the species had previously been reported, according to the Handbook (Munro 1957c), only from New South Wales; Marshall (1964) added Queensland.

Meristic characters. In this section and the next the datum for (a) precedes that for (b); entries in parentheses are measurements, mm, entries for proportions in square brackets are values by Waite (1899) for a specimen $210 \mathrm{~mm}$ in total length, and those given by McCulloch (1929), based on two specimens, 190, $200 \mathrm{~mm}$. 


\section{E.0.G. Scott}

D. $78,79[75,75-87]$. A. $58,68[67,67-74]$. V. $4 / 4,4 / 4[4,4]$. P. $6,6 / 5,5$ $[-,-]$. C. $16,16[17,15-16]$. L. lat with 89 pores in main segment between operculum and hypural joint, 24 in supratemporal segment, 4 tubules and 20 small verrucae on cauda $1,94+23+18[102+19+18,92-96]$. L. $\operatorname{tr}: 26 / 1 / 35,25 / 1 / 34[-, 27 / 1 / 36]$.

Dimensions and proportions. Head $(24.0,19.2 \mathrm{~mm}), 5.5,5.0[6.6$, 'about 6'] in Ls $(131,96)$; or $6.2,5.7$ in Lt $(149,109)$. Depth at front of eyes $(17.6,14.5) 7.4,6.6$, at back of eyes $(29.3,18.2) 4.5,5.3$, at operculun $(44.0,28.0) 3.0,3.4$; maximum depth, occurring a little behind, about at, one third of standard length $(53.0,34.0) 2.5$, $2.8[2.54,2.5]$; chord of arc of base of caudal rays $(9.5,6.2) 13.8,15.5$ in $L s$.

Upper eye, eyebal1 only (see Norman 1934, p. 50) (5.1, 3.7) 4.7, 5.2 [eye 5.1 'eye about $\left.4^{\bar{i}}\right]$, including soft orbit $(5.9,4.0) 4.0,4.8$; Iower eye $(5.0,3.3), 4.8,5.8$ and $(6.1,4.2) 3.9,4.6$; interorbita1, between eyebal1s $(2.4,2.3) 10.0,8.3$ [interorbital 1.5 in eye; giving about 6 in head, - ], between inner edges of orbits (1.8, $0.5) 13.3,38.4$, the soft fleshy orbital rims highly tumid in (b); snout to level of front eyebal1 (4.6, 4.9) 5.2, 4.3; shortest distance (callipers) between upper eyeball and dorsal profile $(3.0,2.1) 8.0,9.1$; shortest distance (callipers) between lower eyebal1 and ventral profile $(5.7,3.5) 4.2,5.5$; interval between middles of outer borders of upper and lower eyebalis $(8.4,7.0) 2.9,2.7$; distance between middles of inferior borders of upper lids (i.e., direct shortest interval between pupils) (6.0, $4.5) 4.0,4.3$; length of maxilla $(6.4,5.0) 3.8,3.8$; length of lower jaw $(9.4,7.0)$ $2.6,2.7$ in head.

First dorsal ray $(2.0,2.0) 12.0,9.6$, ray at middle of fin $(12.1,9.1) 2.0,2.1$, last ray $(12.0,11.6) 2.0,1.7[-$, posterior ray 1.5$]$; first ana 1 ray $(5.1,4.1) 4.7$, 4.7, ray at middle of $\mathrm{fin}(12.0,9.0) 2.0,2.1$, last ray $(13.3,12.0) 1.8,1.6[-$, posterior ray 1.5$]$; median caudal ray $(18.0,13.0) 1.3,1.5$; longest, 3rd, 3rd [-, 2nd] ventral ray of ocular side $(8.2,7.2) 2.9,27[-, 3.2]$, base of that fin (9.8, $5.3) 5.0,5.6$; longest, 3 rd, 3rd ventral ray of blind side $(7.8,6.0) 3.1,3.2$, base of that $f$ in $(5.1,3.7) 4.7,5.2$; length of pectoral of ocular side, without filamentous terminal appendage to one ray in $(b)(2.9,2.1) 8.3,9.1$, transverse extent of that fin $(3.7,2.9) 6.5,6.6$; length of pectoral of blind side $(2.9,1.9) 8.3,10.1$, transverse extent of that fin $(3.5,2.9) 7.0,6.6$ in head.

Remarks. The original description by Macleay (1882, p. 14), based on an example five inches in length, is brief: the only quantitative items are D+C+A 148, height about twice and a half in total length, eyes about their vertical diameter apart, ventrais about equal in size. Pectorals are mistakenly stated not to be present (the fins can readily be overlooked, not only because they are small, but also because they are partly overlain, and largely hidden from view, by the gill cover). More extended accounts, each accompanied by a figure, have been given by waite (1899, p. 126, p1. XXXI) and McCulloch (1916, p. 61, pl. VIII, fig. 2).

Our specimens have been compared with these descriptions and illustrations. As may be seen from the data set out above, they exhibit, in general, reasonably good agreement with the quantitative items in them. Attention may be called, however, to the unexpectedly low anal count in $(a)$, namely, 58, as against 68 in $(b)$ and a reported range of 67-74 [this variation exceeds that noted for any member of the family diagnosed in "the Handbook, the greatest discrepancy being 10 on 65 in Aesopia microcephalus (Gunther 1862)]. This feature inevitably raised a question as to whether two species were perhaps involved. However, apart from this point, and the presence of somewhat better developed pectorals in this fish as compared with (b) (see remarks on generic status, below), no significant difference could be observed between the two; while, on the positive side, they exhibit very close agreement morphologically, even in respect of quite minor features.

Some additional observations follow. Upper eye slightly in advance of lower. 
164

\section{Tasmanian Fishes}

Mouth to below $0.2,0.3$ of lower eye; twisted to blind side. Dorsal and ventral surfaces of head and much of opercular region on blind side with numerous small cirri; opercular border fringed. Dorsal and anal rays in front half, or so, of fin with white processes, on front rays extending along most of their length, successively decreasing in number backward to a single process. Lateral lines similar on right and left sides, but supratemporal branch less conspicuous on blind side. Scales ctenoid on both sides; extending on to dorsal and anal rays on both sides, rather more extensively on dorsal. Tube of anterior nostril on ocular side extending beyond orbital border of lower eye. Ventrals subequal, their bases contiguous, enclosed at their origin in a short common cutaneous sac, and the two anterior rays joined by a common membrane investing their proximal one-fourth or one-fifth; fins otherwise wholly separate from one another; no attachment to anal. In McCulloch's figure free margin of caudal extends but little beyond curve formed by continuation of borders of dorsal and anal, and is broadly rounded; in Waite's figure the caudal (while still fully confluent with dorsal and anal) has more the appearance of a separate structure, and is bluntly pointed; in both our examples the second condition obtains. On the other hand, in color pattern the fin here agrees more closely in both cases with McCulloch's figure, in which a submarginal black band is briefly bordered externally with white, whereas Waite's figure depicts a terminal black band: in our fish the dark portion is brown, not black.

General color of ocular side of $(a)$ very dark brownish (warm mid-brown where scales are missing) of (b) light brown (fawn where scales are missing); of blind side whitish (where scales are missing, yellowish flesh, pale flesh). About a score of darker cross bars (somewhat indistinct, or faded out, in posterior one-third of fish), of which 5 (including an imperfect one before eyes) are on head; bars a little narrower than their interspaces anteriorly, subequal to them at middle of length: only obscure and faint indications of a continuation of them on to fins (cf. McCulloch's figure, contrast Waite's). Dorsal and anal are depicted in Waite's plate as for the most part evenly colored, with a white border, while McCulloch's figure - reproduced in the Handbook (Munro 1957c, fig. 494) - shows about half fin height occupied by a darker medial band: specimen $(a)$ exhibits the second condition (band approaching black), (b) the first. Pectoral of right side more or less concolorous with trunk nearby, that of left side white or whitish. Right ventral mostly dusky olivaceous, first ray lighter; left whitish. Lips on ocular side and cirri on head flesh colored, lips on blind side white.

Generic status. Zebrias Jordan \& Snyder, 1901 was separated from Brachirus Swainson, 1839 (equated, if Swainson's name is considered invalid, with Synoptura Cantor, 1849) to accomodate certain species (orthotype, Solea zebrina Temminck \& Schlegel) in which the pectoral, instead of exhibiting well-developed rays arising from a short base, the fin being free of the branchiostegal membrane, has more or less rudimentary rays arising from a broad base, the fin being connected by a folded membrane to the upper part of the branchiostegal membrane, resulting in the formation of a funnel-1ike access to the branchial cavity. Zebrias is recognised in the Handbook, but is included in Brachirus by Norman (1926, p. 292) and in (the equivalent) Synaptura by Weber \& de Beaufort (1929, p. 167). The latter justify their rejection of Zebrias by noting 'in some species a transistory arrangement between these extremes exists (e.g. S. panoides and $z e b r a$ ) in which the base of the pectoral is broader than usual, the upper rays are well developed and where a slight connection exists with the base of the pectoral and the branchiostegal membrane.'

Our two examples throw an interesting sidelight on the matter. In all four pectorals the base is broad, and there is some connection with the branchiostegal membrane. However, the extent and character of the resultant structure show considerable variation, being much less fumel-like in (b) than in (a). Further, while in (b) both fins have the form of a visually undifferentiated membranous lamina, from the evenly curved free border of which project several flexible pointed processes, representing tips of rays, in (a) the left has typical bayonet-like rays, clearly traceable throughout their length, and the membrane between them is strongly scalloped, the right fin 


\section{E.0.G. Scott}

being much similar, but having the rays somewhat less fully developed. The existence in our fish of a direct connection between pectoral fin and branchiostegal membrane is here accepted as a convenient ground for referring them to Zebrias.

\section{Family BRACHIONICHTHYIDAE}

The three species reported from Tasmania - Brachionichthys hirsutus (Lacépède, 1804), Brachionichthys politus (Richardson, 1849), Sympterichthys Zaevis (Lacépède, 1804), al1 of which have this State as type locality - have been keyed (along with the South Australian Sympterichthys verrucosus McCulloch \& Waite, 1918) in Part VI (1953,p. 158), and an account, with figure, given of a specimen of the first-named species from the Derwent estuary. The taxonomic status of these three nominal forms remains unresolved: it seems not improbable, however, that only one or at most two species occur here.

\section{Genus BRACHIONICHTHYS Bleeker, 1885}

Brachionichthys Bleeker, 1885, Verh. Akad, Amsterdam, 2, p. 112. Logotype, B. politus Bleeker [ = Chironectes politus Richardson].

\section{Brachionichthys hirsutus (Lacépède, 1804)}

Lophius hipsutus Lacépède, 1804, Ann. Mus. D'Hist. Nat., 4, pp. 202 and 210, pl. LV, fig. 3. Type locality: New Holland (Baudin) [ = Tasmania, fide McCu1loch (1929,p. 409)].

Chironectes punctatus Cuvier, 1817, Mem. Mus. d'Hist. Nat. Paris, 3, p. 434, p1. XVIII, figs. 2, 5 (skeleton). Based on Lophius hirsutus Lacépède (Péron) [Tasmania].

Distribution. Though recorded from New South Wales, and quite commonly taken in the Derwent, southern Tasmania, this species has very seldom been noticed from our northern coast, and has hitherto been unrepresented by other than southern material in the Queen Victoria Museum's collections. It is not clear whether this is due to scarcity of the fish or to non-use of suitable collecting techniques. Some observations are here made on two specimens, (a) Ls 90.2, Lt 118.0, (b) Ls 93.1, Lt 123.2, dredged off Cape Portland, at the north-eastern corner of Tasmania, on 8 September 1974 by $\mathrm{Mr} \mathrm{J}$. Shea. Data for (a) are given first.

Meristic characters. D.III, 18; III, 18. A.9;10. P.7;7. V.4;4. C.9(1+6+2); $8(1+5+2)$. The presence in (b) of only 8 caudal rays is quite exceptional.

Genera1 body form. Head: trunk: tail $=28.3,31.2: 21.6,19.1: 50.1,49.7$. In terms of the set of variable factors of body-form proposed by Gregory (1928), these fish are specifiable as mesosomatic, gasterion preapical, apex median, gasterion anterior, mesonotic, mesogastric, nomopygidial, opisthion preuranic.

Chief dimensions as Tls. Length to termination of first dorsal 215, 242; base from spine I (i11icium-bearing) to end of membrane 233, 267, from spine II 200, 237 (both measurements, callipers). Length (chord) of dorsal spine I 165, 140; spine II (chord) 231, 274; 1st ray 164, 242; longest (3rd, 3rd) ray 200, 322; 1ast ray 80, 145 . Length to origin, termination of second dorsal 310,$304 ; 863,884$; of ana1 565,$559 ; 887,892$. Length of 1 st ana1 ray 145,153 ; longest $(7$ th, 7 th) ray 150,$195 ; 1$ last ray 100,150 . Length to pectoral origin (felt-for) 232, 272, to middle of axillary membrane 397 , 430 ; length of fin from felt-for origin to 'elbow' 265,301 , from 'elbow' to tip of longest ray 259, 275; longest (3rd, 4th) ray 200, 226. Length to ventral origin 166, 177; length of fin 234, 236; longest (3rd, 4th) ray 183, 215. Length to vent 499, 503. Head to end of felt-for operculum 283, 311, length to gill opening (anterior base of tube) 382, 419. Snout 74, 75; eye 68, 73; interorbita1 76, 83; maxil1a $100,122$. Depth at front of eyes 177, 183, back of eyes 216, 210, operculum 222, 274, gi11 open- 


\section{Tasmanian Fishes}

ing 211,215 , vent 200,193 ; maximum depth of trunk (= that of head) 222, 274; depth of caudal peduncle 77,75 .

Other features. Jaws subequal. Maxilla to below front of eye. Illicium lanceolate, compactly pleated; its spine smooth, flexible. Teeth, mucigerous system, spinules and scales as previously described (1953).

Coloration. General color greyish or buff. Head, body, trunk profusely marked with dark reddish brown spots, frequently tending to form regular lines, but seldom coalescing to constitute short bars. A light roundish area below interdorsal, more clearly developed in (b) and with dark centre on left side of that individual; a light spot above gill opening, another above anal origin, latter barely defined in $(\alpha)$. First dorsal spotted moderately in $(a)$, heavily in $(b)$. Second dorsal in (a) with very few spots in basa $1 \frac{1}{2}-4 / 5$, numerous small spots along free border, in $(b)$ whitish basally, white area round base of first ray, several other small whitish areas, remainder rather heavily spotted. Anal white, immaculate in $(a)$, with 4 small dark spots in hind half in (b). Pectoral dark-spotted lightly in $(a)$, heavily in (b). Ventral with about a score of spots in (b), half as many in $(a)$. Caudal of $(a)$ well spotted in dista1, barely in proximal, ha1f; of (b) proximal one-fourth immaculate, rest heavily spotted, particularly so dista11y.

\section{Family ALUTERIDAE}

Part IX (1960, p. 96) provided a provisional key to the local members of the family, taking note of 16 species, some probably nominal, reported from Tasmania to that time: included in the key was Navodon setosus (Waite, 1899), the first record for this State being made in that contribution. Species since added to our 1 ist are Navodon multiradiatus (Gunther,1870), Brachaluteres wolfei Scott, 1969, the former in Part XX (1974b) of this series, the latter in a separate paper (Scott 1969). Navodon degeni (Regan, 1902) is here reported.

Genus NAVODON Whitley, 1939

Navodon Whitley, 1939, Aust. Zool., 6(2), p. 179. Orthotype, Balistes australis Donovan.

\section{Navodon degeni (Regan, 1902)}

Pseudomonacanthus degeni Regan, 1902, Froc. Zool. Soc. Iond., 2(2), p. 299, p1. XXIV, fig. 1. Type locality, Melbourne Market.

Cantherhines degeni McCu1loch, 1929, Aust. Mus. Mem., 5(3), p. 419.

Navodon degeni Fraser-Brunner, 1941, Ann. Mag. Nat. Hist. (ser. 11), 8(45), p. 185. NeZusetta degeni Whitley, 1964, Proc. Limn. Soc. N.S.W., 89(1), p. 59.

Tasmanian record. This species, originally reported from Victoria, appears not hitherto to have been met with elsewhere. A Tasmanian example, Ls 210, Lt 250, was collected by Mr C.R. Steel at Wynyard on 15 November 1973; Q.V.M. Reg. No. 1973/5/117.

Fin counts. D. I, 34. A.33. P.13/13. C.11 $(1+9+1)$.

Principal dimensions. Values as TLS are followed in parentheses by measurements in mn. Length to origin of first dorsal 333 (70), termination 398 (83.5); of second dorsal $586(123), 883$ (185.5); of anal 581 (122), 893 (187.5). Length of dorsal spine 85 (17.8). Length to pectoral origin $314(66)$, length of fin 138 (29), oblique width of base $50(10.5)$. Length to pelvic spine 476 (100), length of spine 14 (3). Length to vent (middle) 550 (115.5). Head to origin of gil1 opening 295 (62), end of opening 324 (68), length of opening between parallels $29(6.0)$, oblique length $60(12.5)$. 
Snout 271 (57), eye 62 (13), interorbital 81 (17). Length of mouth cleft 21 (4.5), width 52 (11). Shortest distance (ca11ipers) from upper end of gill opening to eye 49 (10.3), from eye to base of dorsal spine 50 (10.5). Depth at front of eyes 290 (61), at middle of gill opening 321 (67), at back of eyes 329 (69), at vent 329 (69); maximum depth with pelvic flap 390 (82), without flap 348 (73); depth of caudal peduncle at ana 1 termination $102(21.5)$, minimum $88(18.5)$. Widths at the same four points 119 (25), 129 (27), 129 (27), 119 (25); maximum width of head 129 (27), of body 133 (28); width of caudal peduncle at anal termination 48 (10), at hypural joint 33 (7).

Comparative proportions. Though clearly conspecific with Regan's Victorian type, Lt 190 (with which it agrees in meristic characters, though a second dorsal spine, noted by Regan as 'scarcely visible', was not detected), the present, somewhat larger, specimen exhibits some interesting variations in proportion as follows (holotype datum first). Depth of body equal to length of head (with pelvic flap 1.2, without flap 1.1, head). Snout $32 / 3(4.4)$ eye diameter, which is equal to $(0.8)$ interorbital. Leng th of gill opening about $2 / 3$ (oblique length 1.0 , horizontal extension 0.5 ) eye. Length of dorsal spine $22 / 5(3.8)$ in head. Pectoral almost as long as (1.6) dorsal spine. Longest, 8 th or 9 th dorsal and anal rays $(8 \mathrm{th}, 8 \mathrm{th}$ ) equal to half head (dorsal 0.51 head, ana 10.49 ).

General features. Regan's description of the holotype is a rather brief one; a more detailed account, based on the present example, is here offered.

Head (taken throughout as length to end of gill opening), trunk, tail in ratio 32.4: 22.6: 45.0. Specification of body form (s.ystem of Gregory 1928) hypsisomatic, gasterion preapical, apex median, gasterion median, mesonotic, mesogastric, leptopygidial, opisthion preuranic.

General form rather elongate, subelliptical, anterior end more rounded than posterior. Dorsal profile back to highest point, in interdorsal, tolerably evenly convex, a trifle flattened in middle portion of snout; convexity decreasing caudad, lapsing to become briefly concave on peduncle. Ventral profile in advance of vent convex overal1, pelvic flap contributing little extra, but with long sha1low median concavity; behind vent subequal to dorsal profile here. Greatest depth 2.6 in $L s, 1.2$ head. Caudal peduncle stout, its leng th 1.2 its least depth, 3.0 in head.

Anal originating barely in advance of dorsa1, at $0.58 \mathrm{Ls}$, ending barely behind dorsa1, at $0.89 \mathrm{Ls}$, its base 1.05 dorsal base, or just less than head. Regan states dorsal and anal rays after reaching 8 th or 9 th decrease to about 20 th, rest being subequal (though his figure seems to show last anal ray longer than some shortly preceding it). In our fish anal rays increase rapidly, in a convex curve, to 8 th, which is half head, thereafter decreasing, in a bold convex curve, most rapid up to about level of middle of base, consistently up to last, 33rd, ray, which is 1.4 in $1 \mathrm{st}, 1.8$ in $20 \mathrm{th}, 4.7$ in $8 \mathrm{th}$. Profile of soft dorsal broadly similar to that of anal, but in neighborhood of 20 th ray several rays subequal, with one, 20 th $(13.0 \mathrm{~mm})$ slightly longer than immediately preceding ray (12.2); longest ray 1.1 longest anal ray. Dorsal spine inserted above posterior border of orbit, wholly behind level of gill opening; length to base exactly one-third Ls; short, 3.8 (cf. Regan, 2.4) in head; anterior border almost straight for three-quarters of its length, then curving in slightly to end at moderately acute point; posterior border straight for nine-tenths of its length, the curvature of the spine-end being provided mainly by anterior border; anterior surface well rounded, wholly covered with very numerous closely-set minute granulations, mostly rounded, some quite bluntly pointed, no spinules present, except three, very small, on right anterior border near middle one-third of length; posterior surface smooth, save for a few granulations from anterior surface just extending round edge, a dark, low mesial ridge, traceable from within 2-3 mm of tip down to about $1 \mathrm{~mm}$ above origin of fin membrane, located at two-thirds height of spine. First dorsal membrane small, low, oblique height about one-sixth eye, extending, mostly as closely 


\section{Tasmanian Fishes}

adherent slip, along about two-thirds of groove housing spine when depressed, this groove extending for full length of spine, deepest and widest in anterior two-thirds, greatest depth about one-fourth eye. Pectoral originating at $0.3 \mathrm{Ls}$, extending 0.6 of distance towards vent, broad, rounded, longest in upper half, all rays simple, beset, most abundantly proximally, with mimute granulations, extending up ray for from about one-tenth to one-fifth of its length. Pelvic spine small, length less than onefourth eye; blunt process, minutely rugose, about a dozen larger, still quite small, mammilloid elevations round margin and near tip. Pelvic shield traceable forward to below anterior one-ninth of snout. Pectoral broad, rounded, longest in upper half, length to origin $0.31 \mathrm{Ls}$, extending 0.59 of distance towards vent, all rays simple, beset, most abundantly proximally, with minute granulations, extending up ray for from about one-tenth to one-fifth of its length. Caudal moderate, length from hypural joint 1.7 , length of median ray 2.0 in head, distal margin markedly and symmetrically sinuous, a central convexity extending behind level of a concavity on either side of it by half an eye diameter; 1st, 11 th rays undivided, 2nd, 10 th with 4 rami, 3rd, 9th with 8 , rest normally with 16 (an occasional failure in final division), rays beset, most abundantly proximally, with minute granulations, extending maximally up ray for three-fourths of its length.

Eye moderate, about equidistant from base of dorsal spine and upper end of gill opening, that distance four-fifths of its diameter; 1 ength to orbit 1.2 in head. Mouth smal1, its antero-posterior extension (including lips) about half its width, the latter one-sixth length of head. In upper jaw two large subtriangular median teeth, contiguous in their distal half (most of exposed portion); flanked on either side by two much smaller, well-separated, less acute teeth, base of inner one on right contiguous with, that on left distinct from, base of large tooth; a soft lobe, resembling a tooth, just external to outer tooth on each side. In lower jaw two distally apposed large teeth like those of upper jaw; outer edge of each continuous with a low ridge-1ike cutting edge, on right side linear, on left somewhat sinuous; an odontiform process, on right side subtriangular, on left subconical, rising from middle one-fifth of ridge. Gill opening with lower end on line joining mouth cleft and middle of caudal peduncle; wholly beneath eye, lower end behind anterior orbital border by 0.4 eye, upper end in advance of posterior orbital border by 0.15 eye ('below hind margin of eye', Regan); its oblique length just less than eye diameter. General feel velvety; scales small, closely set, with 6-12 knobs or blunt spinules in an arc along hind border; varying in size by a factor of 2 or more, coarser on lips and nearby. Very small scales extend all over low, but well-developed, sharply delimited basal sheath of soft dorsal and less extensive anal sheath.

Coloration. Ground color fairly uniform somewhat yellowish grey; more dusky, less yellowish on most of snout above a line from mouth to gill opening, with continuation back under dorsal spine, also in small area behind and below pectoral; basal sheaths of soft dorsal and anal brownish olivaceous; lips, chin, throat light, or very light, grey; teeth hyaline or faintly yellow. The diagnosis of the body-form, according to the system of Gregory (1928) is hypsisomatic, gasterion preapical, apex median, gasterion median, hypsinotic, bathygastric, leptopygidial, opisthion preuranic.

Pattern comprises long dark stripe near hinder part of dorsal profile, breaking up anteriorly into one or two short bars and spots, and on head, trunk, tail many dark spots, usually conspicuous and well-rounded, sometimes, especially on snout, less intense, less clearly delimited, much more numerous than in the holotype as figured (Regan 1902, pl. XXIV, fig. 1); pattern differing in detail on the two sides. On left side pronounced dark bar originating at second one-third of interdorsal, running back, without noticeable alteration in width, to meet a subvertical bar on upper half of caudal peduncle at hypural, its course more or less following curve of body, but gradually approaching profile caudad, its maximum distance from it about twice its own width or about half eye; its course continued forward by a short stripe, subequal to eye, and an arc of 7 spots, decreasing in size and intensity forwards, most anterior 
E.0.G. Scott

in advance of eye by half eye diameter: spots on snout 30-40, more or less confined to upper half, the anterior ones very faint, mainly disposed in 6-7 lines radiating forward and downward from eye: on trunk and tail a row of 14, evenly spaced, and, except for one above anal termination, in a continuous curve, more or less following ventral profile from anal origin to last one-fourth of caudal peduncle, distant anteriorly from profile by about an eye diameter, posteriorly by half as much; short row of 13 between main row and anal base above hind half of latter; 18 on lower one-third of flank between head and vent, fairly closely, somewhat irregularly, set, 7 continuing in the general sense of the line of 14 ; about 25 others, mostly irregularly disposed, but 5 , larger than the rest, largest about half eye diameter, or twice modal size, above and behind posterior part of anal base, in 2 pairs, followed by 1 on middle of caudal peduncle. Chief difference exhibited by right side: dark stripe below dorsal profile extending unbroken somewhat further forward to below end of spine-groove, followed by short stripe below groove and some indeterminate spots; 22 spots in a more or less continuous series from near end of caudal peduncle, above ventral profile to below level of middle of pectoral, surmounted by just separate arc of 3 closely below pectoral; rest disposed overall in nuch the same way as on left, with some individual variation, including occurrence of 2 on middle of flank about above vent, not present on $1 \mathrm{eft}$.

Dorsal spine in general greenish brown, median ridge on posterior surface dark brownish; exposed membrane greenish brown except lower half of distal border, which is blackish; inside greenish amber spine-groove closely adherent strip of membrane brown. Dorsal and anal rays bright blue, their extreme, somewhat spatulate, tips whitish; dorsal membrane virtually hyaline, anal very pale yellowish. Pectoral rays bright green, septa white, tips white or hyaline; membrane colorless. Uppermost and lowermost caudal rays colorless, rest chiefly bright blue, proximal one-sixth or so obscurely greenish, tips very light bluish or whitish; membrane hyaline.

Remarks. The most noteworthy differences exhibited by our specimen when compared with the holotype include rather shorter snout (4.4, of. $32 / 3$, in head), much shorter dorsal spine (3.8, ef. $22 / 5$, in head), decidedly more extensive pattern of spots, simpler, and differently tinted, color pattern in caudal fin. These would seem to represent individual variations only.

Fin patterns. Neither the dorsal nor the anal rays are completely specifiable by two or three sets of length-number equations, the middle region of both presenting no simple recognizable pattern (though partly specifiable in terms of several subsets each with few members): equations can be formulated, however, for the first 8 rays of each fin, the last 10 of the dorsal and the last 8 of the anal. It is of interest to observe that, while in the majority of species examined earlier, and in all those dealt with elsewhere in this paper, the length-number relation is of the form $L=b N^{k}$ [with $N^{I}$, a serial number ccunting cephalad, or otherwise conventionally in reverse sequence, commonly substituted for $N$ in descending series], yielding a linear plotting when expressed as $\log L=k \log N+\log b$, the appropriate equation for (specifiable) dorsal and anal rays in the present fish is $L=k \log N+c$, and that for pectoral rays is $\log N=k N+c$.

For dorsal rays 1-8 $L=30.072 \log N+7.4627$ : measured (in parentheses, predicted) lengths, mm, $8.0(7.5), 15.2(16.5), 22.0(21.8), 26.2(25.6), 28.8(28.5), 30.9$ (31.0), $32.3(32.9), 34.8(34.6) ; t=36.654$. For rays $25-34 L=4.4121 \log N^{1}+6.5157: 6.5$

$(6.5), 8.0(7.8), 8.6(8.5), 8.9(9.1), 9.4(9.6), 10.0(9.9), 10.0(10.2), 10.5(10.5)$, $11.0(10.7), 11.2(10.9) ; t=10.560$.

For anal rays $I-8 L=25.879 \log N+10.3141: 10.2(10.3), 18.0$ (18.1), 23.2 (22.7), $26.9(25.9), 29.2(28.4), 30.5(30.5), 32.0(32.1), 33.3(33.6) ; t=37.889$. For rays $26-33 L=3.7306 \log N+7.0273: 7.1(7.0), 8.4(8.2), 8.7(8.8), 8.9(9.3), 9.2(9.6)$, $10.0(9.9), 10.5(10.2), 10.6(10.4) ; t=9.668$. 


\section{Tasmanian Fishes}

In the pectoral measured lengths (right fin) of the 2 members of the first subset are 23.0, 24.0. For the remaining rays, 3-13, $\log L=-0.3413 N+1.4220: 23.9$ (24.4), $22.4(22.6), 21.0(20.9), 19.5(19.5), 18.0(17.8), 16.8(16.5), 15.4(15.2), 14.0$ $(14.1), 13.1(13.0), 11.9(12.0), 11.0(11.1) ; t=62.156$.

Pectoral patterns in other species. The occurrence in Navodon degeni of an arithlog number-length pattern, not previously encountered in a pectoral fin, has prompted a preliminary examination of the position obtaining in the pectoral of some other members of the genus. In 3 examples of Navodon australis (Donovan, 1824), (a) Ls 167, Lt 204, (b) 186,220 , (c) 191, 225, it has been found al1 pectoral rays can be treated as 3 subsets, each specified by an equation of the form $\log L=k N+c$; further, in these specimens the subsets exhibit intersection, giving a continuous formulation for the whole $f$ in. Similar subsets were recognized in an example of $N$. multiradiatus (Gunther, 1870), Ls 260, Lt 330, and in an example of N. hippocrepis (Quoy and Gaimard 1824), Ls 279, Lt 328; the second and third sets only intersecting in the former species. The relevant data are summarized below; but the subject calls for further and wider investigation.

For specimens $(a),(b),(c)$ of $N$. austratis the members of the first subset are rays $1-4,1-4,1-3$; of the second subset 4-8, 4-9,3-10; of the third subset 8-14, 9-14, 10-14, respectively. For the first subset the coefficients of $N$ are 0.01931 , $0.01794,0.02753$; for the second subset - 0.01416, - 0.02739, - 0.04596; for the third subset $-0.03281,-0.03921,-0.01952$. The corresponding independent terms are $1.2154,1.2207,1.2430 ; 1.2982,1.3173,1.3437 ; 1.2537,1.1958,1.2369$. Values of $t$ are $9.394,11.157,24.139 ; 11.915,43.327,17.287 ; 30.900,10.962,23.214$. For $N$. multiradiatus, with subsets of rays 1-3, 4-8, 8-14, the coefficients of $N$ are -0.02174 , - 0.01781, - 0.4182; the independent terms $1.3364,1.4152,1.3687 ; t=69.054,14.264$, 29.631. For N. hippocrepis, with subsets 1-4, 4-7,7-13 the coefficients of $N$ are $-0.009403,-0.01306,-0.04343$; the independent terms $1.3593,1.4011,1.3966$; $t=$ $5.065,6.358,78.641$.

Fits for regression equations are (as indicated by high $t$ values) very good. For 48 items for $N$. australis ( $i, e$, including double appearance of a ray) predicted lengths differ from measured lengths by $0.0-2.7, \bar{x} 0.76+0.11 \%$; for 15 items for $N$. multiradiatus by $0.0-1.5, \bar{x} 0.67 \pm 0.14 \%$; for 15 items for $N$. hippocrepis by $0.0-2.5$, $\bar{x} 1.20+0.17 \%$

\section{REFERENCES}

Anon., 1974: Australian marine and freshwater fisheries production 1972-73 - catch by species. Aust. fisher., 33(6), 30-35.

Berg, L.S., 1940: The classification of fishes both recent and fossil. Trav. Inst. Acad. Sci. U.R.S.S., 5(2), 86-517, figs 1-190 (in Russian, not seen). Edition in Russian and English, Ann Arbor, Mich., U.S.A. (J.W. Edwards).

de Beaufort, L.F.: see Weber, M. \& L.F. de Beaufort, 1929.

Doak, W., 1972: FISHES OF THE NEW ZEALAND REGION. Auckland, Hodder \& Stoughton.

Fowler, H.W., 1908: A collection of fishes from Victoria, Australia. Proc. Acad. Nat. Sci. Phizad., (1907), 419-444, 10 figs.

Greenwood, P.H., Rosen, D.E., Weitzman, S.H. G Myers, G.S., 1966: Phyletic studies of teleostean fishes, with a provisional classification of living forms. BuZZ. U.S. Mus. Nat. Hist., 131(4), 339-456, text figs 1-9, p1. 21-23, charts 1-32.

Gregory, W.K., 1928: Studies on the body-forms of fishes. Zoologica, 8(6), 325-421, figs $117-455$. 


\section{E.0.G. Scott}

Güther, A., 1880: Report on the shore fishes procured during the voyage of H.M.S. 'Challenger' in the years 1873-76. Rept 'Challenger', Zool., 1(6), 1-82, pls I-XXX I I.

Johnston, R.M., 1883: General and critical observations on the fishes of Tasmania, with a classified catalogue of all known species. Pap. Proc. R. Soc. Tasm., (1882), 58-144.

, 1891: Further observations on the fishes and fishing industries of Tasmania, together with a revised list of indigenous species. Pap. Proc. R. Soc. Tasm., (1890), 22-46.

Jordan, D.S., 1923: A classification of fishes including families and genera as far as known. Stanf. publ. Univ. ser., biol. sci., $\underline{3}(2), i-x+77-243$.

Kurth, D., 1954: A new bothid fish from eastern Tasmania. Pap. Proc. R. Soc. Tasm., 88, 45-48, $1 \mathrm{p} 1$.

Ling Roth, H., 1899: THE ABORIGINES OF TASMANIA; 2nd ed. Halifax, England, F. King \& Sons.

Lord, C.E., 1923: A 1ist of the fishes of Tasmania. Pap. Proc. R. Soc. Tasm., (1922), $60-73$.

, 1927: A list of the fishes of Tasmania. J. pan-Pac. res. Inst., 2(4), $11-16$.

, and Scott, H.H., 1924: A SYNOPSIS OF THE VERTEBRATE ANIMALS OF TASMANIA. Hobart, Oldham, Beddome \& Meredith.

McCulloch, A.R., 1911: Report on the fishes obtained by the F.I.S. 'Endeavour' on the coasts of Queensland, New South Wales, Victoria, South Australia and Tasmania. Part 1. Zool. res. Endeavour, 1(1), 1-87, pls i-xvi, text figs 1-19.

, 1916: Ichthyological items. Mem. QLd Mus., 5, 58-69, p1s vii-ix, 4 text figs.

1920: Studies in Australian fishes. No. 6. With a description of a new Girelzops from the Kermadec Islands. Reo. Aust. Mus., 13(2), 41-71, p1s $X-X I V$, text figs $1-3$.

, 1927: THE FISHES AND FISH-LIKE ANIMALS OF NEW SOUTH WALES; 2nd ed., with additions by G.P. Whitley. Sydney, Royal Zool. Soc. N.S.W.

, 1929: A check-list of the fishes recorded from Australia. Aust. Mus. Mem. $\underline{5}(1-4)$ (part 4, index, 1930), i-ix + 1-534.

Macleay, W., 1881: Descriptive catalogue of the fishes of Australia. Part 4. Froc. Linn. Soc. N.S.W., 6(2), 202-387.

, 1882: Notes on the Pleuronectidae of Port Jackson, with descriptions of two hitherto unobserved species. Eroc. Linn. Soc. N.S.W., $7(1), 11-15$.

Marsha11, T.C., 1964: FISHES OF THE GREAT BARRIER REEF AND COASTAL WATERS OF QUEENSLAND. Sydney, Halstead Press.

Munro, I.S.R,, 1957a: Handbook of Australian fishes, 11, 43-48; in Fisher. news 2 . (now Aust. fisher.), $16(5)$.

1957b: Handbook of Australian fishes, 16, 65-68; in Fisher. news 2. (now Aust. fisher.), 16(10). 


\section{Tasmanian Fishes}

, 1957c: Handbook of Australian fishes, 17, 69-72; in Fisher. newsl. (now Aust.' fisher.), $16(11)$.

, 1957d: Handbook of Australian fishes, 18, 73-76; in Fisher. newsl. (now Aust. fisher.), $16(12)$.

, 1958a: Handbook of Australian fishes, 20, 81-84; in Fisher. news2. (now Aust. fisher.), $17(2)$.

, 1958b: Handbook of Australian fishes, 28, 113-116; in Fisher. newsl. (now Aust. fisher.), $17(10)$.

Norman, J.R., 1926: A report on the flatfishes (Heterosomata) collected by the F.I.S. 'Endeavour', with a synopsis of the flatfishes of Australia and a revision of the subfamily Rhombosoleinae. Biol. res. Endeavour, 5(5), 219-308, figs 1-15.

1934: A systematic monograph of the flatfishes (Heterosomata): vol. 1, Psettodidae, Bothidae, Pleuronectidae. London, British Museum.

Ogilby, J.D., 1886: Catalogue of the fishes of New South Wales with their principa1 synonyms. Rept Commis. Fisher. N.S.W., appendix A, 1-67.

01sen, A.M., 1958: New fish records and notes on some uncommon Tasmanian species. Pap. Proc. R. Soc. Tasm., 92, 155-159.

Parrott, A.W., 1959: SEA ANGLERS' FISHES OF AUSTRALIA. Adelaide, Hodder \& Stoughton.

Robins, A.J., 1952: Further observations on the striped tuna, Katsuwonus pelamis L., in eastern Australian waters, and its relation to surface temperature. Aust. J. Mar. Freshw. Res., 3(2), 101-110.

Roughley, T.C., 1916: FISHES OF AUSTRALIA AND THEIR TECHNOLOGY. Sydney, Government Printer.

Schmidt, E.J., 1928: The fresh-water eels of Australia. With some remarks on the short-finned species of Anguizla. Rec. Aust. Mus., 16(4), 179-210, figs 1-14.

Scott, E.0.G., 1934-1974: Observations on some Tasmanian fishes. Parts I-XX in this journal (except part XVI, Aust. zool., 15(2), 160-177, figs 1-2). Contributions here cited: 1935, part II, 63-73, pl. V. 1936, part III, 113-129, text figs 1-3. 1953, part VI, 141-165, text figs 1-4. 1957, part VIII, 145-156. 1960, part IX, 87-101, text fig. 1. 1961, part X, 49-65, text figs 1-3, 1963, part XI, 1-31, text figs 1-8. 1964, part XII, 85-106, text fig. 1. 1965, part XIII, 53-65, text fig. 1. 1971, part XVIII, 119-143, text fig. 1. 1974a, part XIX, 247-289, text figs 1-2. 1974b, part XX, 171-197, text figs 1-4.

, 1942: Syngnathus tuckeri sp. nov.: a new Tasmanian pipefish. Rec. Q. Viat. Mus., $1(1), 17-20, \mathrm{pl}$. V.

, 1969: Description of Brachaluteres wolfei, sp. nov. (Aluteridae) and first Tasmanian record of Urolophus paucimaculatus Dixon, 1969 (Urolophidae). Pap. Froc. R. Soc. Tasm., 103, 35-45, text figs 1-2.

, 1970: First Tasmanian record of the gulf gurnet perch, Neosebastes panticus McCulloch \& Waite, 1918 (Scorpaenidae), with reports of poisoning by this species and other Tasmanian fishes. Aust. zool., 15(3), 234-241, fig. 1.

Scott, T.D., 1962: THE MARINE AND FRESH WATER FISHES OF SOUTH AUSTRALIA. Adelaide, Government Printer. 


\section{E.0.G. Scott}

Serventy, D.L., 1941: The Australian tunas. C.S.T.R. Pamph. 104, 1-48, pls 1-4, figs $1-9$.

Stead, D.G., 1906: FISHES OF AUSTRALIA. A POPULAR AND SYSTEMATIC GUIDE TO THE STUDY OF THE WEALTH IN OUR WATERS. Sydney, William Brooks.

, 1908: THE EDIBLE FISHES OF NEW SOUTH WALES; THEIR PRESENT IMPORTANCE AND THEIR POTENTIALITIES. Sydney, Government Printer.

Waite, E.R., 1899: Scientific results of the trawling expedition of H.M.C.S. 'Thetis', Introduction and fishes. Aust. Mus. Mem., 4, 1-132, frontspiece, pls i-xxx, text figs $1-10$.

, 1921: Illustrated catalogue of the fishes of South Australia. Rec. $S$. -Aust. Mus., 2(1), 1-208, p1. i, 293 text figs.

Weber, M., \& de Beaufort, L.F., 1929: THE FISHES OF THE INDO-AUSTRALIAN ARCHIPELAGO, 5. Leiden, E.J. Brill.

Whitley, G.P., 1944: New sharks and fishes from Western. Australia. Aust. zool., 10 (3), $252-273$, figs. $1-6$.

figs 1-11.

, 1948: Studies in ichthyology, No. 13. Rec. Aust. Mus., 22(1), 74-94,

1964: A survey of Australian ichthyology; Presidential address.

Appendix B, Name-list of the fishes recorded from Australia. Proc. Linn. Soo. N.S.W., $89(1), 32-60$.

, 1968: A check-1ist of the fishes recorded from the New Zealand region. Aust. zool., 15(1), 1-102, figs 1-2. 